\title{
Advances in conducting polymer-based thermoelectric materials and devices
}

\author{
Tianyi Cao ${ }^{1, \#}$, Xiao-Lei Shi ${ }^{2, \#}$, Jin Zou ${ }^{1,3}$, Zhi-Gang Chen ${ }^{2,1}$ \\ 1School of Mechanical and Mining Engineering, The University of Queensland, Brisbane, Queensland 4072, Australia. \\ ${ }^{2}$ Centre for Future Materials, University of Southern Queensland, Springfield Central, Queensland 4300, Australia. \\ ${ }^{3}$ Centre for Microscopy and Microanalysis, The University of Queensland, Brisbane, Queensland 4072, Australia. \\ ${ }^{\#}$ Authors contributed equally.
}

Correspondence to: Prof. Zhi-Gang Chen, Centre for Future Materials, University of Southern Queensland, Springfield Central, Queensland 4300, Australia. E-mail: zhigang.chen@usq.edu.au

How to cite this article: Cao T, Shi XL, Zou J, Chen ZG. Advances in conducting polymer-based thermoelectric materials and devices. Microstructures 2021;1:2021007. https://dx.doi.org/10.20517/microstructures.2021.06

Received: 20 Aug 2021 First Decision: 9 Sep 2021 Revised: 15 Sep 2021 Accepted: 24 Sep 2021 Available online: 30 Sep 2021

Academic Editor: Shujun Zhang Copy Editor: Xi-Jun Chen Production Editor: Xi-Jun Chen

\begin{abstract}
Conducting polymer-based thermoelectric materials are considered the most promising candidates for applying to wearable thermoelectric devices because of their high electrical conductivities, flexibility, stability, and low-toxicity features. Therefore, a timely review is needed to comprehensively overview their most recent progress in the last few years, considering the rapid development of thermoelectric conducting polymers. In this work, we carefully summarize recent advances in thermoelectric conducting polymers from aspects of their mechanisms, synthesis, micro/nanostructures, mechanical/thermoelectric properties, and related functional devices. A few state-of-theart thermoelectric conducting polymers, including poly(3,4-ethylenedioxythiophene)poly(styrenesulfonate), poly(3-hexylthiophene), polyaniline, and polypyrrole, are highlighted in detail. In the end, we point out the challenges, controversies, and outlooks of conducting polymers for future thermoelectric applications.
\end{abstract}

Keywords: Thermoelectric, conducting polymer, synthesis, performance, device

\section{INTRODUCTION}

With the depletion of indispensable non-renewable energy sources such as petroleum and natural gas, extensive investigations focus on sustainable technologies for harvesting green energy from wind, solar, bioenergy, and waste heat ${ }^{[1]}$. Thermoelectric (TE) materials and devices, with the capability for direct 
conversion between heat and electricity, show great potentials as sustainable and green technologies ${ }^{[2-6]}$. In order to evaluate the TE potential of a material, a dimensionless figure of merit $Z T$ is defined by $Z T=S^{2} \sigma T \kappa^{-1}$, where $S$ is the Seebeck coefficient, $\sigma$ is the electric conductivity, $T$ is the absolute temperature, and $\kappa$ is the thermal conductivity. Thus, $S^{2} \sigma$ can be described as the power factor. Both a high $S^{2} \sigma$ and low $\kappa$ are needed to achieve a high $Z T$ for a targeted material ${ }^{[1,7-10]}$.

Since the 1950s, early TE materials such as $\mathrm{Bi}_{2} \mathrm{Te}_{3}{ }^{[1,12]}$ have been widely used in various fields ${ }^{[13]}$, but their performance is not ideal with a $Z T$ of up to one unit. With the rapid development, nowadays many thermoelectric materials, such as $\mathrm{PbTe}^{[14]}, \mathrm{Pr}_{2} \mathrm{CoFeO}_{6}{ }^{[15]}, \mathrm{SrTiO}_{3}{ }^{[16]}, \mathrm{SnTe}^{[17,18]}, \mathrm{Cu}_{2} \mathrm{Se}^{[19]}, \mathrm{SnSe}^{[20-24]}$, and

$\mathrm{GeTe}^{[25-28]}$, have exhibited high ZTs of $>2$, by using the rational electronic band structure design for boosting $S^{2} \sigma$, and/or by using micro/nanostructure manipulations for achieving low $\kappa$. In addition to conventional bulk TE materials, conducting polymer-based thermoelectric materials is increasingly popular and shows high flexibility and promising TE performance. These conducting polymer-based thermoelectric materials target flexible TE generators (F-TEGs) with broad practical applications such as charging wearable and portable electronics ${ }^{[6]}$. As can be seen from Figure $1 \mathrm{~A}^{[10,22]}$, F-TEGs tend to serve implantable and wearable electronic devices ${ }^{[30]}$ such as smart glasses, smart watches, and trackers, which only need low energy demand, as suggested in Figure $1 \mathrm{~B}^{[31]}$. The increase in demand for lightweight, high-performance, and inexpensive products is driving the growth of the global conductive polymer market. Specifically, the conductive polymer industry was pegged at $\$ 3.46$ billion in 2020 and is projected to reach $\$ 5.76$ billion with a compound annual growth rate of $8.3 \%$ from 2021 to $2027^{[32]}$. Therefore, high-performance, low-toxic, and high-stability F-TEGs are the most promising candidates to meet the demand of the future electronic market ${ }^{[33-35]}$. Similar to conventional TE devices, the structure of F-TEGs can be described as the combination of several pairs of $\mathrm{p}$ - and n-type TE materials, as shown in Figure $1 \mathrm{C}^{[1,36-38]}$.

In recent years, conducting polymers have exhibited promising TE performance, benefited from many advanced strategies such as doping, pre- and post-treatments, and hybridization. Figure 1D summarizes $S^{2} \sigma$ values of the state-of-the-art conducting polymers developed in recent 5 years, including polypyrrole $(\mathrm{PPy})^{[39-43]}$, polyaniline (PANI) $)^{[44-48]}$, poly( 3 -hexylthiophene) (P3HT) ${ }^{[49-54]}$, and poly $(3,4-$ ethylenedioxythiophene)poly(styrenesulfonate) (PEDOT: PSS ${ }^{[55-59]}$, which possess the high possibility to be applied in wearable F-TEGs ${ }^{[60]}$. Considering the rapid development of conducting polymers that target FTEGs, a timely review is needed to overview their most recent progress comprehensively. We carefully summarize the advances in state-of-the-art conducting polymers from the aspects of mechanisms, synthesis, micro/nanostructures, mechanical and TE properties, and F-TEGs. Particularly, the state-of-the-art systems, including PEDOT: PSS, P3HT, PANI, and PPy, are detailed discussed. In the end, we point out the challenges, controversies, and outlooks of conducting polymers for future TE applications ${ }^{[61]}$.

\section{FUNDAMENTAL OF CONDUCTING POLYMERS}

\section{Charge transport}

Based on the Seebeck effect ${ }^{[2-66]}$, TEGs can generate electricity by utilizing temperature difference $\Delta T^{[67]}$. Therefore, charge transport is a vital part of the TE conversion. For polymer-based TE materials, the charge transport mechanism is different from conventional inorganic TE materials. In conducting polymers, the structure of the $\pi$-conjugated skeleton is closely relevant to charge transport. Figure $2 \mathrm{~A}$ illustrates the valence band ( $\pi$ orbital), the conduction band ( $\pi^{*}$ orbital), and the band gap of trans-polyacetylene, one kind of typical conducting polymers ${ }^{[68]}$. Due to the weak interaction force between organic molecules, the thermal drive causes the dynamic disorder of the molecules, which directly affects the mobility of carriers. Such a band structure is similar to conventional inorganic TE materials, where the charge transport is determined by conduction/valence bands and band-gap value. Therefore, rational doping can effectively 

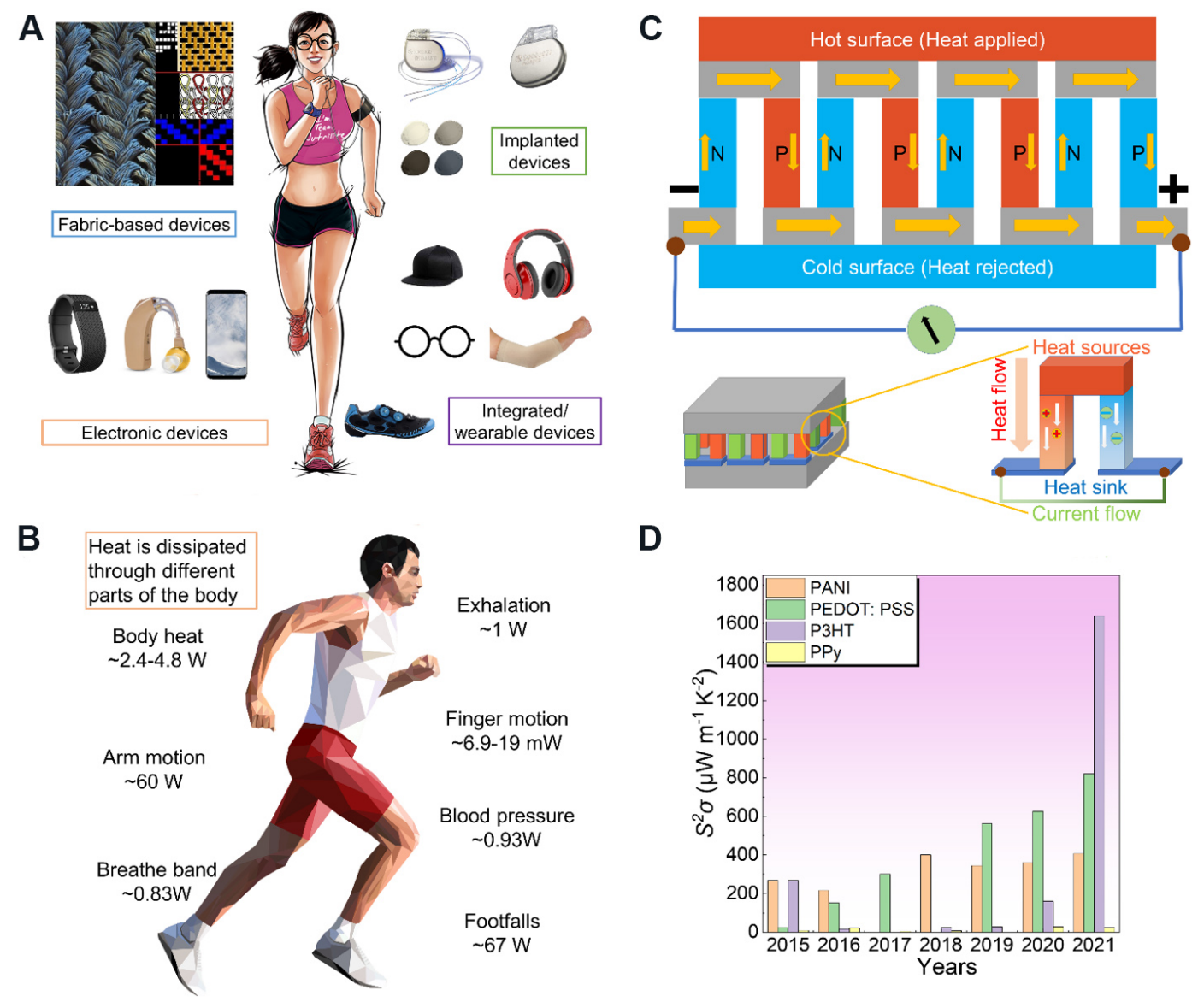

D

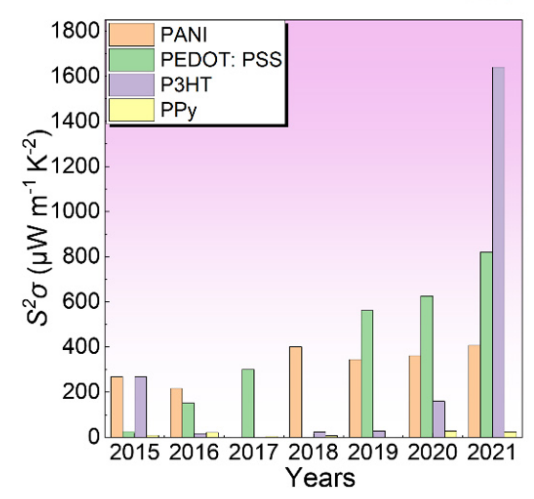

Figure 1. (A) Wearable and implantable devices, clothing, and objects. Reproduced with permission ${ }^{[10]}$. Copyright 2019 Wiley. Reproduced with permission ${ }^{[29]}$. Copyright 2020 Cambridge University Press. (B) Heat dissipated from various parts of the human body ${ }^{[31]}$. Copyright 2020 Wiley. (C) Schematic diagram for the assembly of thermoelectric devices ${ }^{[1]}$. Copyright 2020 ACS publications. (D) Comparison of $S^{2} \sigma$ values for the state of-the-art polypyrrole (PPy $)^{[39-43]}$, polyaniline (PANI $)^{[44-48]}$, poly (3-hexylthiophene) $(\mathrm{P} 3 \mathrm{HTT})^{[49-54]}$, and poly(3,4-ethylenedioxythiophene)poly(styrenesulfonate) (PEDOT: PSS) ${ }^{[55-59]}$.

alter the band structure and, in turn, significantly improve the charge transport of conducting polymers.

Because the charge transport mechanism is complicated in organic molecules, a few different models have been developed to investigate charge transport behaviors. Bimolecular reaction (Marcus model) is one of the typical models. According to this model, the basic reaction can be described as $\mathrm{D}^{-}+\mathrm{A} \rightarrow \mathrm{D}+\mathrm{A}^{-[69]}$. Figure $2 \mathrm{~B}$ describes the energy change based on the reaction by the Marcus model, where $\Delta G^{*}$ is the energy barrier and related to the charge transfer integral $(t)$. In this model, $\Delta G^{*}=(\lambda-2 t)^{2}(4 \lambda)^{-1}=\lambda / 4-t(t<\lambda)$, and $\lambda=$ $f\left(q_{\mathrm{R}}-q_{\mathrm{P}}\right)^{2} / 2^{[70]}$. Here, $f$ is the oscillation intensity, and $q_{\mathrm{R}}$ and $q_{\mathrm{P}}$ are coordinate reactants and products. Marcus theory can be linked to charge transfer speed and carrier mobility $\mu$. According to the relationship between $\lambda$ and $2 t$, the charge transfer can be divided into band-like and hopping models. In the band-like transport model, carriers move freely in the energy band. If there is no external electric field, carriers only have free thermal motion, while if an electric field is applied, carriers move under the influence of the electric field. Figure $2 \mathrm{C}^{[71]}$ shows the carrier transport path with or without an external electric field. With increasing the temperature, $\sigma$ and $\mu$ decrease. This model is suitable for conducting polymers with high intrinsic $\sigma$ and materials with low doping concentration. In terms of the hopping model, conducting polymers are difficult to form a high-regularity structure like crystals; therefore, the localized charge in amorphous organics moves in a hopping manner. In solid materials, the localized charge appears "self- 

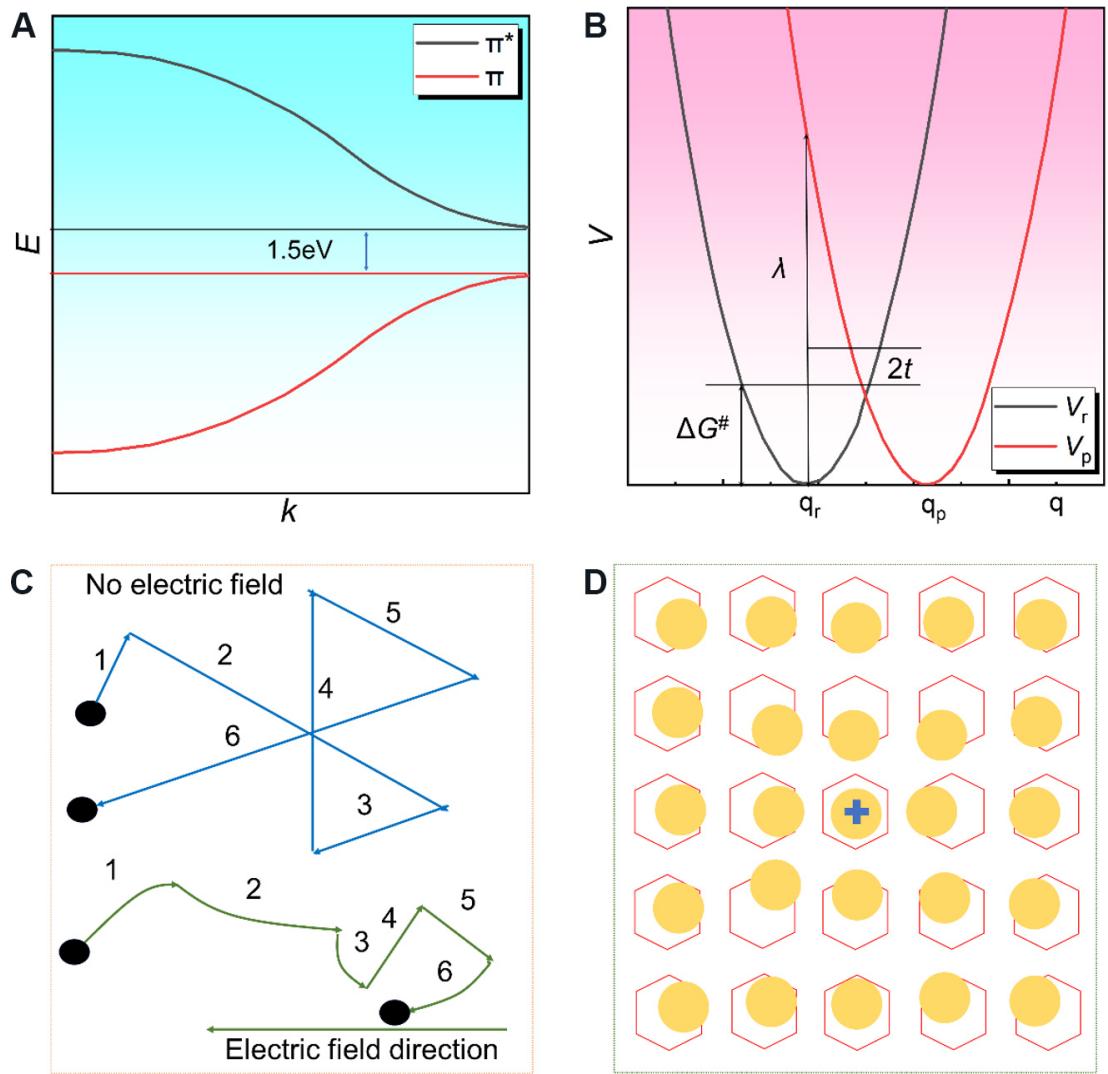

Figure 2. (A) Valence band $\pi$ and conduction band $\pi^{\star}$ orbital energy diagram of trans-polyacetylene. Reproduced with permission ${ }^{[68]}$. Copyright 2012 Royal Society of Chemistry. (B) Potential energy diagram of charge transfer reaction in conducting polymers. Reproduced with permission ${ }^{[70]}$. Copyright 2007 CRC Press. (C) Schematic diagram of the electron transport path in conducting polymers. Reproduced with permission ${ }^{[71]}$. Copyright 2006 Oxford University Press. (D) Schematic diagram of the formation of polarons in conducting polymers under the influence of positive charges. Reproduced with permission ${ }^{[70]}$. Copyright 2007 CRC Press.

trapped", which causes obvious displacement of the surrounding atoms. This charge forms a polaron with the polarized cloud induced around. Among them, the polarization effect of conducting polymers mainly comes from the polarization of the surrounding $\pi$ electron cloud, as shown in Figure 2D.

As mentioned above, overloaded carriers move driven by the temperature field so that $S$ can be defined as the entropy change caused by the thermally excited carrier transport. Besides, the core mechanism of the TE conversion reveals the effect of carrier transport related to $\sigma$ and $S$. The conversion mechanism also indicates that $\sigma$ and $S$ are mutually restrictive; they are both directly affected by the carrier concentration $n$ ( $n_{\mathrm{p}}$ for the materials with holes as major carriers, and $n_{\mathrm{e}}$ for the materials with electrons as major carriers). Interestingly, $S$ decreases as $n$ increases, and $\sigma$ is the opposite. At the same time, the electronic thermal conductivity $\kappa_{\mathrm{e}}$ is directly related to $n$. For conducting polymers, peaks of these three parameters roughly appear in the interval of $n$ of $10^{19}-10^{21} \mathrm{~cm}^{-3}$. The current challenge of explaining the charge transport mechanism of conducting polymers is that $S$ and $\sigma$ are influenced by different transport mechanisms, although researchers have tried to develop different transport models. To date, the developed models include (1) The nearest-neighbor model describes the transport of electronic charges from Site A to Site B, with other charges filling Site A simultaneously, which is used when the conductive polymers are heavily used doped. Particularly, under thermal excitation, this model is generally used to explain the carrier transport behaviors. However, the apparent shortcoming is low accuracy as well as the sites distance limitation $^{[72]}$. (2) Variable-range hopping model is used to describe localized states distributed in a large 
energy band, which determines $\sigma$ without neglecting the energy-dependent term. Generally, this model can be adapted in conductive polymer-doped situations ${ }^{[72]}$. (3) Mobility edge model is suitable for describing charges excited into delocalized states. Compared with the hopping model, the mobility edge model matches the conductive polymers with higher $\sigma^{[73-75]}$. (4) Transport edge model is suitable for some advanced conductive polymers with a higher $\sigma$ similar to metals, which are more able to follow $S \propto \sigma^{1 / 4}$ empirical power law ${ }^{[75]}$. (5) Heterogeneous media model is suitable for describing disordered regions of conductive polymer with poor $\sigma$. However, conductive polymers are not completely disorders or crystalline; instead, the small crystalline domains range from 10 to $50 \mathrm{~nm}$, connect according to disordered regions and connect by several extended polymer chains. Hence, the model is effective when the conductive polymer has both high and poor $\sigma$ sections in series ${ }^{[76]}$.

\section{Thermal transport}

$\kappa$ is an inherent property of most materials. Usually, $\kappa$ is calculated using Fourier's law ${ }^{[77,78]}$. The $\kappa$ value is affected by both phonons and electrons because $\kappa$ is composed of $\kappa_{\mathrm{e}}$ (the influence of electrons) and $\kappa_{\mathrm{l}}$ (the influence of phonon $)^{[1,79]} \cdot \kappa_{\mathrm{e}}$ is the heat transfer affected by electron diffusion, which has a positive correlation with $\sigma$. while, $\kappa_{1}$ does not influence $\sigma$; instead, $\kappa_{1}$ is related to the vibration of the lattice. Generally, a hierarchical structure with multi-dimensional structural imperfections can sharply decrease $\kappa_{1}^{[00,81]}$. Generally, conductive polymers are typical low-crystallinity materials with entanglement, chain ends, voids, and impurities as intrinsic defects ${ }^{[82]}$. Entanglement is one of the most common defects mainly found in thick fibers, leading to interchain transport instead of intrachain transport and, in turn, altering the phonon transport behavior ${ }^{[83]}$. Chain ends shorten the effective heat transport because the covalent bonds of the polymer chain dominate the $\kappa^{[84]}$. Voids influence the effective $\kappa$ with its morphology, volume, and pore size. Among these, the pore size has the most significant influence on phonon transport ${ }^{[85]}$. As for impurities, their volume fraction, interface thermal resistance, particle size, and aspect ratio also affect the phonon transport behavior ${ }^{[86]}$. Therefore, phonon transfer plays a crucial role in $\kappa$ of polymers ${ }^{[87]}$.

Figure $3 \mathrm{~A}$ compares temperature-dependent $\kappa$ of conducting polymers with different structures, including disordered polymer, organic crystal, Poly(ethylene glycol)-block-poly(propylene glycol)-blockpoly(ethylene glycol) triblock copolymer (PEPG) treated PEDOT: PSS $^{[88]}$ with high crystallinity and low crystallinity. Previous works tried to explain the relationship between $\kappa$ of insulating crystal change and thermodynamics. Peierls first introduced the theory by conservation of momentum ${ }^{[8]}$. In a conventional process, phonons exhibit momentum conservation. However, in the Umklapp process, momentum is not conserved, and the conservation needs to consider the changes brought by the movement of the entire crystal. As shown in Figure $3 \mathrm{~B}^{[00]}$, in the theoretical process, Phonon-3 can be superimposed by Phonon-1 and Phonon-2. In the Umklapp process, because of the discrete nature of the atomic lattice, there is a minimum phonon vibration wavelength that represents the maximum allowable vector wave. The vector wave generated by the combination of two phonons is greater than this allowable value. In this situation, the direction of the phonons can be deflected, and the lattice vector $G$ needs to be given to balance the differences between the theoretical vector sum and the actual vector sum.

Phonon transport in pure polymer composites is shown in Figure 3C. Phonon transport between the same types of atoms is almost directly transported without scattering. However, phonons can be scattered if the atoms are different in type, or there are defects in the microstructure or impurities. Polymer materials usually have the characteristics of these types of phonon motion at the same time. The internal defects and discontinuous interfaces strengthen the phonon scattering, and the heat transfer efficiency can be significantly suppressed ${ }^{[9-93]}$. It should be noted that the thermal transport mechanism of organic materials is different from that of inorganic materials with crystalline structures ${ }^{[94]}$. Therefore, phonon transport is almost carried out with no apparent scattering behavior, as shown in Figure $3 \mathrm{D}^{[78,93]}$. Figure $3 \mathrm{E}$ shows the 

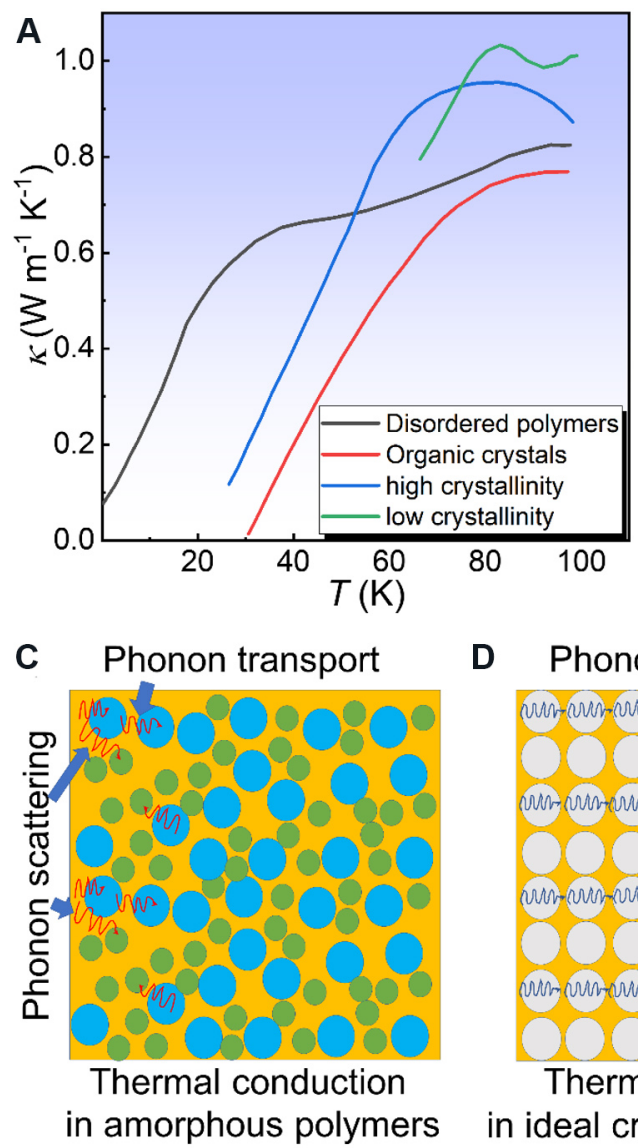

B

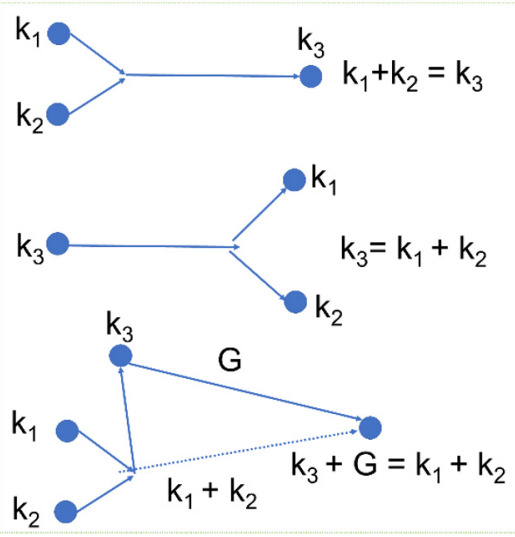

D Phonon transport

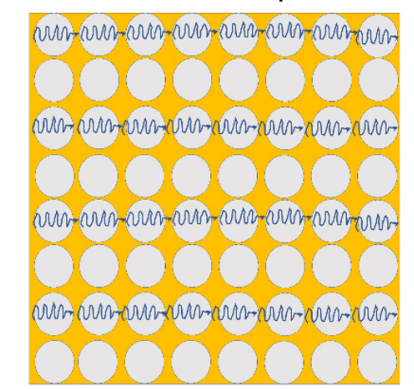

Thermal conduction in ideal crystalline materials
E Phonon transport

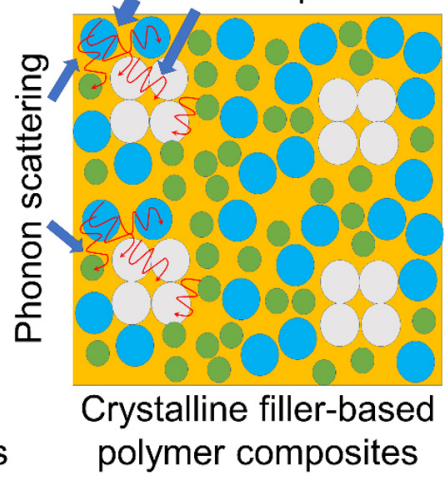

Figure 3. (A) Temperature-dependent $\kappa$ of conducting polymers with various structures. Reproduced with permission ${ }^{[68]}$ Copyright Royal Society of Chemistry; (B) schematic diagram of phonon transport and scattering vector. Reproduced with permission ${ }^{[90]}$. Copyright ProQuest Dissertations Publishing. Phonon movement in (C) amorphous polymer, (D) crystalline materials, and (E) hybrid materials, respectively. Reproduced with permission ${ }^{[78]}$. Copyright ELSEVIER.

phonon transport behavior in inorganic/organic hybrid materials. Generally, the phonon transport in hybrid materials is difficult to be directly predicted by the phonon transport mechanisms of conducting polymers and inorganic materials ${ }^{[95]}$.

\section{Doping}

$\sigma$ and $S$ of pure or unprocessed conducting polymers are usually unsatisfactory. Rational doping can well tune $n$, which is closely related to $\sigma$ and $S$. Doping methods and mechanisms of organic and inorganic materials are usually different, which are mainly derived from the different transport models and mechanisms between these materials. According to different doping mechanisms, there are many doping types, including chemical doping, optical doping, interface doping, and electrochemical doping. Chemical doping is based on the interaction between molecules, which can greatly change the properties of conducting polymers ${ }^{[96]}$. Figure $4 \mathrm{~A}$ indicates the main effect of chemical doping for conducting polymers, in which fillers with oxidation and reduction properties are introduced into polymers to increase the number of carriers, to increase $\sigma^{[97]}$. A typical example is a camphanic acid, a typical dopant to provide the electron for $\mathrm{P}_{3} \mathrm{HT}^{[97]}$. Figure $4 \mathrm{~B}$ shows a schematic diagram of mixed doping, in which the matrix material and the dopant are well mixed before deposition so that the dopant molecules are well dispersed in the matrix material. As can be seen, 2,3,5,6-Tetrafluoro-7,7,8,8-tetracyanoquinodimethane (F4TCNQ) as a dopant is uniformly dispersed in $\mathrm{P} 3 \mathrm{HT}$. As a result, such doping can greatly improve $n$. However, the materials 

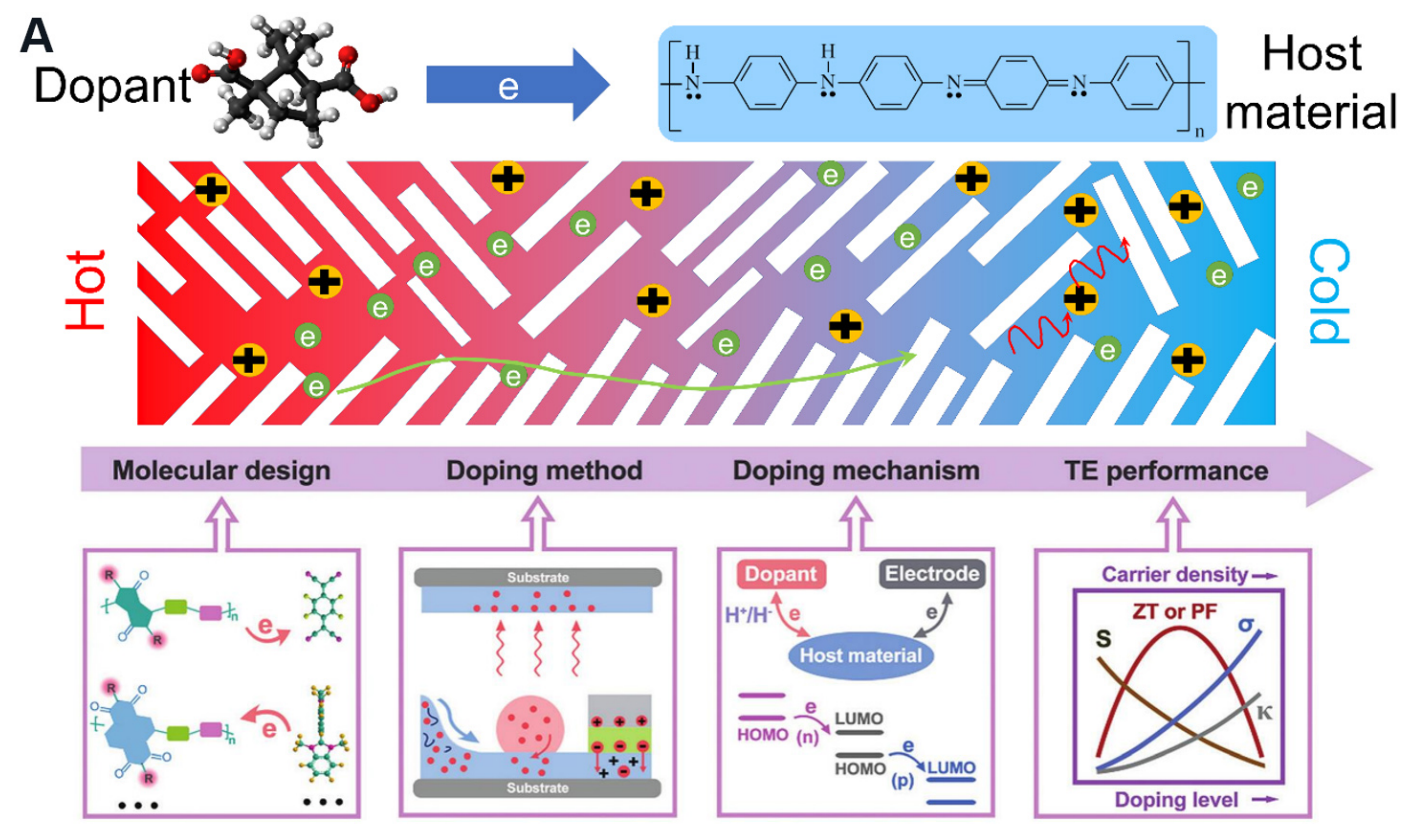

B

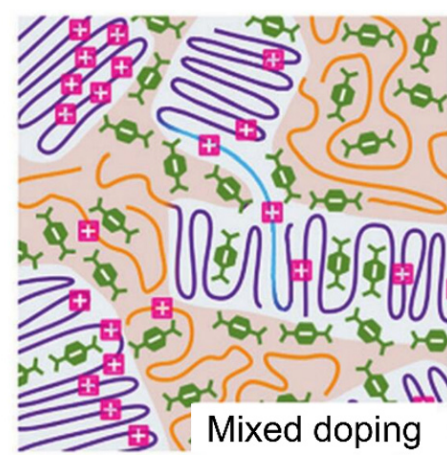

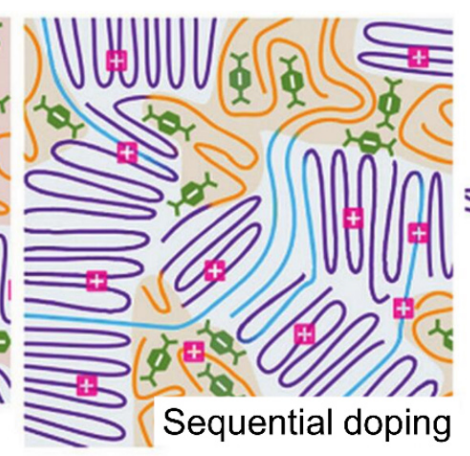

I P3HT polaron

F4TCNQ anion

Crystalline P3HT

Amorphous

$\mathrm{P} 3 \mathrm{HT}$

\section{Tied chains}

Figure 4. Schematic diagrams of (A) chemical doping in conducting polymers and (B) different specific embodiments and internal structure of doping. Reproduced with permission ${ }^{[96]}$. Copyright 2020 Royal Society of Chemistry. TE: Thermoelectric; F4TCNQ: 2,3,5,6Tetrafluoro-7,7,8,8-tetracyanoquinodimethane; P3HT: poly(3-hexylthiophene).

prepared by this doping method cannot adapt to most solvents, and such a doping method is also difficult to restore the undoped morphology. It should be noted that this dopant might also affect the crystallinity of the polymer, which may result in the change of other properties. It was reported that with increasing the concentration of $\mathrm{F} 4 \mathrm{CNQ}$ dopant, the aggregation of $\mathrm{P} 3 \mathrm{HT}$ became more significant. Compared with their original state, the newly-formed complex $\mathrm{P} 3 \mathrm{HT}$ chains are flatter ${ }^{[98]}$. Also, the increased F4CNQ dopant could result in reduced crystalline domain size and increased amorphous pentacene phase, which caused the decrease of $\mu^{[99]}$. Besides, F4CNQ anions mainly exist in amorphous regions of polymer films and side chains, which is possible to form $\pi$ stacking eutectic phenomenon and, in turn, increase the $\mu^{[100]}$. In terms of the sequential doping method based on the high-quality matrix material, the dopant can achieve good dispersion in the matrix material. Compared with previous doping, sequential doping can maintain the morphology of the matrix material and is also easier to follow-up processing. By using this doping method, the $\mathrm{P} 3 \mathrm{HT}$ molecules can be wrapped by a group of doped ions, forming a discontinuous polymer structure. Such doping contributes to a much higher $\sigma^{[96]}$. 


\section{Pre- and post-treatment}

Conducting polymers are suitable for secondary doping to order their microstructures to improve the composition and morphology of conducting polymers without changing the doping level ${ }^{[101]}$. Secondary doping can be followed by the doping operation to increase $S$ and $\sigma$ simultaneously ${ }^{[102]}$. There are many types of pre- and post-treatments to achieve this goal. For example, polar solvent treatment can enhance the order of the polymer microstructure, such as dimethyl sulfoxide (DMSO) that is generally used to process PEDOT: PSS, and its $\sigma$ can be improved by a hundred times. This is attributed to the high dielectric constant of DMSO and the induced strong screening effects ${ }^{[103]}$. DMSO as a unary solvent treatment has been proven to increase $\sigma$ without changing the doping level significantly, so the impact on $S$ is negligible. Therefore, it is possible to improve performance by maintaining $S$ value. In addition to polar solvent treatment, post-treatment is another effective way to order the microstructure of conducting polymers. During post-treatment, the excess insulating phase can be removed by phase segregation to increase $\sigma$. Commonly used post-treatment methods include employing $\mathrm{DMSO}^{[104]}$, methanol ${ }^{[105]}, \mathrm{N}, \mathrm{N}$ dimethylformamide (DMF) of $\mathrm{CuCl}_{2}^{[106]}$, formic acid ${ }^{[105]}$, sulfuric acid $^{[107,108]}$, and then rinse. Taking PEDOT: PSS as an example, $\mathrm{H}_{3} \mathrm{SO}_{4}{ }^{+}$and $\mathrm{HSO}_{4}{ }^{-}$can interact with positively charged $\mathrm{PEDOT}^{+}$and negatively charged PSS. By inducing phase segregation, part of the PSS is removed, which increases the possibility of PEDOT forming crystals. PSS and $\mathrm{H}_{2} \mathrm{SO}_{4}$ are removed by cleaning with excess deionized water. After rational posttreatment, the PEDOT has been reported with the highest $\sigma$ of up to $4200 \mathrm{~S} \mathrm{~cm}^{-1[107]}$. Pre-treatment is usually combined with post-treatment, which aims to improve $S$ to improve $S^{2} \sigma$, but it may cause potential intermediate damage on the microstructures of conducting polymers ${ }^{[93]}$. Similar to post-treatment, pretreatment can effectively improve the $\sigma$ of the polymer. For example, pre-treatments such as nitrogen and argon use plasma to improve the surface properties of the fabric, including wettability, hydrophobicity, and dyeability ${ }^{[109]}$. Besides, pre-treatments also include solvent treatment and oxidant treatment, which impact electrical and mechanical conductive polymers ${ }^{[110]}$. Furthermore, sequential treatment combines secondary doping and doping, which simultaneously increases $S$ and $\sigma$. As mentioned before, doping can tune the oxidation level to improve the band structure and density of states to improve $S$, while secondary doping cannot change the oxidation level of the polymer.

\section{Energy filtering and quantum confinement}

The energy filtering effect is proposed from the interfaces between different materials, and it can effectively improve $S$ without reducing $\sigma$. Theoretically, the alternating energy barrier layer realizes a filter that only allows high-energy carriers to pass through, thereby increasing the entropy change of carrier transport. Generally, both inorganic materials such as superlattices ${ }^{[11,112]}$ and organic-inorganic hybrid systems ${ }^{[113-115]}$ can show significant energy filtering effects, especially for hybrid materials with obviously different band structures. For example, researchers used carbon nanotubes (CNTs) and redox graphene ${ }^{[116]}$ to dope conducting polymers such as $\mathrm{PEDOT}^{[117]}, \mathrm{PANI}^{[118]}$, and $\mathrm{PPy}^{[119]}$. By the effective energy filtering, $\sigma$ can increase by 1-2 orders of magnitude without decreases in $S^{[120]}$. However, it should be noted that the principle of energy filtering is still not very clear; therefore, it is usually difficult to find suitable hybrid materials to achieve high TE performance. Furthermore, in terms of the quantum confinement effect, when the sample size reaches the nanometer level, the electronic energy level near the Fermi level splits from a continuous state into a discrete energy level, and the physical property of the material significantly changes. However, the technology for preparing organic TE materials with orderly low-dimensional structure is not mature, limiting the possibility of its broad application. Therefore, the method to control the growth of materials at the molecular level is an important research direction for conducting polymer-based thermoelectrics. 


\section{ADVANCED CONDUCTING POLYMERS}

With the development of conducting polymers-based TE materials, their TE performance has been greatly improved. To illustrate the progress clearly, we firstly make the following summary ${ }^{[4,50-52,54,55,121-175]}$ : Table 1 provides the fundamental structures of conducting polymers; Table 2 summarizes the TE properties of different conducting polymers; Table 3 shows the performance of devices composed of conducting polymers.

\section{PPy}

Polypyrrole (PPy) is a solid polymer formed by oxidative polymerization of pyrrole, which is widely used in

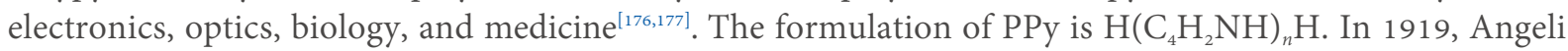
and Pieroni reported the first batch of PPy examples of pyrrole black prepared by pyrrole magnesium bromide $^{[178]}$. Electrochemical synthesis and chemical oxidation are the most commonly used methods to fabricate $\mathrm{PPy} \mathrm{y}^{[179,180]}$. The chemical oxidation of pyrrole can be expressed as:

$n \mathrm{C}_{4} \mathrm{H}_{4} \mathrm{NH}+2 n \mathrm{FeCl}_{3} \rightarrow\left(\mathrm{C}_{4} \mathrm{H}_{2} \mathrm{NH}\right)_{n}+2 n \mathrm{FeCl}_{2}+2 n \mathrm{HCl}$

The mechanism of chemical oxidation is considered as the formation of pi-radical cation $\mathrm{C}_{4} \mathrm{H}_{4} \mathrm{NH}^{+[181]}$. This electrophile attacks the $\mathrm{C}-2$ carbon of the unoxidized pyrrole molecule, producing a dimeric cation $\left[\left(\mathrm{C}_{4} \mathrm{H}_{4}\right.\right.$ $\left.\mathrm{NH})_{2}\right]^{++}$. Thus, conductive forms of PPy are prepared by oxidation ("p-doping") of the polymer, expressed as:

$$
\left(\mathrm{C}_{4} \mathrm{H}_{2} \mathrm{NH}\right)_{n}+0.2 \mathrm{X} \rightarrow\left[\left(\mathrm{C}_{4} \mathrm{H}_{2} \mathrm{NH}\right)_{n} \mathrm{X}_{0.2}\right]
$$

A high-performance PPy was discovered in 2017, fabricated by a chemical oxidation polymerization method $^{[182]}$. In this method, cetyltrimethyl ammonium bromide was dissolved in deionized water and then added to the pyrrole monomer. The black precipitates were obtained using deionized water and ethanol to wash the products generated from the oxidation reaction, as shown in Figure 5A. With increasing the polymerization time, the diameter of the PPy nanowires did not significantly change, but the curling degree of the nanowires was significantly decreased, as indicated in Figure 5B. Besides, the nanowires produced at $0.21 \mathrm{~mol} \mathrm{~L}^{-1}$ oxidant concentration were straighter than the products produced at $0.28 \mathrm{~mol} \mathrm{~L}^{-1}$ and $0.14 \mathrm{~mol} \mathrm{~L}^{-1}$ concentrations, confirming that the polymerization time and oxidant concentration can affect the morphology of PPy. Researchers also use ammonium peroxydisulfate (APS), $\mathrm{Fe}_{2}\left(\mathrm{SO}_{4}\right)_{3}$, and $\mathrm{FeCl}_{3}$ to investigate the oxidation effects on PPy. When APS was used as an oxidizing agent, it was in the form of nanowires, as shown in Figure $5 \mathrm{C}$. When $\mathrm{Fe}^{3+}$ was used as an oxidizing agent, the product was agglomerated, particularly when $\mathrm{FeCl}_{3}$ was used as the oxidizing agent; the agglomeration of the product formed a cauliflower-like morphology. This result indicates that APS is a preferred choice for forming PPy nanowires.

Moreover, the difference in the appearance of the product was caused by the difference in the reaction medium. The clear appearance of nanowires is formed by $\mathrm{H}_{2} \mathrm{O}: \mathrm{EtOH}$ ratio $(3: 1)$. When pure EtOH was used, it formed a flat surface, as shown in Figure 5D. Figure 5E indicates the TE performance of PPy nanowires synthesized under different APS concentrations. When the concentration was $0.21 \mathrm{~mol} \mathrm{~L}^{-1}, \sigma, S$, and $S^{2} \sigma$ reach the maximum values, which are $221.7 \mathrm{~S} \mathrm{~cm}^{-1}, 10.1 \mu \mathrm{V} \mathrm{K}^{-1}$, and $22.6 \times 10^{-3} \mu \mathrm{W} \mathrm{m}^{-1} \mathrm{~K}^{-2}$, respectively. $\sigma$ decreases as the diameter of the nanowire increases. With different oxidants, the overall performance of the PPy nanowires was significantly higher than other types [Figure $5 \mathrm{~F}$ ]. Furthermore, the reaction medium also has an obvious influence on TE performance. As shown in Figure 5G, both $S^{2} \sigma$ and $\sigma$ are the best when PPy nanowires are prepared in pure water. In contrast, with increasing the content of 
Table 1. Structure of conductive polymers for thermoelectric applications

\begin{tabular}{l} 
Name of the polymers \\
\hline Polypyrrole (PPy) \\
Poly(3-hexylthiophene-2,5-diyl) (P3HT) \\
Polyacetylene \\
Poly[K $x$ ( 3 (Ni-ett)]
\end{tabular}

EtOH in the reaction medium, the overall performance gradually decreases ${ }^{[182]}$.

In addition to these works, researchers are trying to break through the TE application limitations of PPy. For example, graphene was used to improve the TE performance of PPy nanowires ${ }^{[183]}$. With increasing the content of graphene, $S$ and $\sigma$ were increased by $20 \%$. Similarly, with increasing the temperature from $300 \mathrm{~K}$ to $380 \mathrm{~K}, S^{2} \sigma$ showed the same trend. At $380 \mathrm{~K}$, the material obtained the highest $S^{2} \sigma$ of $1.01 \mu \mathrm{W} \mathrm{m} \mathrm{K}^{-1}$, which was improved by 3.3 times compared with pure PPy nanowires. The performance of PPy nanotube, PPy nanowire, and PPy particle was also compared ${ }^{[183]}$. Besides, by inserting PPy into reduced graphene oxide, graphene nanosheets were prevented from agglomerating while improving the carrier transport ${ }^{[184]}$. As a result, good flexibility, good mechanical strength, and high $\sigma$ were achieved. The prepared samples had an $S^{2} \sigma 135$ times higher than that of the pure PPy nanotube at room temperature, and exhibited high TE stability after repeated bending ${ }^{[183]}$.

Like adding graphene, single-walled carbon nanotubes (SWCNT) were used to improve the TE properties of PPy. An in-situ polymerization method was used to induce PPy to grow along the regular SWCNT surface $^{[185]}$. No significant changes in $\kappa$ were observed, but the ZT was 55 times higher than that of pure $\mathrm{PPy}^{[185]}$. Moreover, PPy and silver were composited into a thin film through a simple nature-friendly opticalchemical process. By changing the concentration and size of Ag particles in the PPy substrate, $\sigma$ was increased from $1.5 \mathrm{~S} \mathrm{~cm}^{-1}$ to $17.3 \mathrm{~S} \mathrm{~cm}^{-1}$, and $\kappa$ was decreased to $0.16 \mathrm{~W} \mathrm{~m}^{-1} \mathrm{~K}^{-1}$. S was slightly decreased in the process. As a result, the $Z T$ of this material reached the maximum value of $\sim 7.4 \times 10^{-3}$ at $355 \mathrm{~K}^{[186]}$. After integrating six groups of thin films into devices, the maximum voltage can reach $6 \mathrm{mV}$ at room temperature, and the output power is $30 \times 10^{-6} \mu \mathrm{W}^{[186]}$. In addition to $\mathrm{Ag}$, Te was also added to the pyrrole polymerization process to improve the crystal structure, morphology, optical, and electrical properties, leading to an $S^{2} \sigma$ of $23.89 \mu \mathrm{W} \mathrm{m}{ }^{-1} \mathrm{~K}^{-2}$, 850 times higher than pure $\mathrm{PPy}^{[39]}$.

Apart from hybrid/composite methods, doping is also used to improve the performance of PPy. For example, $\mathrm{FeCl}_{3}$ can be used as an oxidant, and p-toluene sulphonic acid (PTSA) can be used as a dopant. When the ratio of PTSA was increased, $\sigma$ was increased from $4.8 \mathrm{~S} \mathrm{~cm}^{-1}$ to $162.7 \mathrm{~S} \mathrm{~cm}^{-1[187]}$. The highest $S^{2} \sigma$ can reach $0.45 \mu \mathrm{W} \mathrm{m}^{-1} \mathrm{~K}^{-2}$. Subsequently, seven sets of films were used to prepare the corresponding 
Table 2. The thermoelectric properties of CPs developed in recent years

\begin{tabular}{|c|c|c|c|c|c|c|c|}
\hline Year & Sample & $Z T$ & $S^{2} \sigma\left(\mu \mathrm{W} \mathrm{m}^{-1} \mathrm{~K}^{-2}\right)$ & $\sigma\left(\mathrm{S} \mathrm{cm}^{-1}\right)$ & $S\left(\mu \mathbf{V} \mathbf{K}^{-1}\right)$ & $\kappa\left(\mathrm{W} \mathrm{m}^{-1} \mathrm{~K}^{-1}\right)$ & Ref. \\
\hline \multicolumn{8}{|l|}{ Р3HT } \\
\hline 2015 & Bar-coated SWCNT/P3HT thin films & - & 105 & $24.8 \pm 9.9$ & $60.7 \pm 2.4$ & - & [121] \\
\hline 2015 & Spray-printed CNT/P3HT & - & $325 \pm 101$ & $345 \pm 88$ & $97 \pm 11$ & - & [122] \\
\hline 2016 & Highly anisotropic P3HT films & 0.1 & 62.4 & 320 & 269 & - & [123] \\
\hline 2016 & {$\left[\mathrm{Fe}\left(\mathrm{TFSI}_{3}\right]_{\text {-doped P3HT powder }}\right.$} & - & 17.10 & 96.1 & 42.2 & - & [52] \\
\hline 2018 & P3HT vapour-doped with F4TCNQ & - & 3 & 22 & 60 & - & [124] \\
\hline 2018 & F4TCNQ-doped P3HT Sb ${ }_{2} \mathrm{Te}_{3}$ based printed & - & 1.6 & 1.6 & 102 & - & [125] \\
\hline 2019 & P3HT/SWCNTs composite films by $\mathrm{HClO}_{4}$ post-treatment & - & 27.99 & $0.6 \pm 0.03$ & $283 \pm 17$ & - & [50] \\
\hline 2020 & Sequentially doped P3HT:F4TCNQ films & - & 56 & 160 & 60 & - & [126] \\
\hline 2020 & P3HT doping with a molybdenum dithiolene & - & 160 & $260 \pm 26$ & 44 & - & [54] \\
\hline 2021 & F4TCNQ-doped CNT yarn/P3HT & 1.1 & $1640-2160$ & 320 & 0.8 & - & [51] \\
\hline 2021 & P3HT dual doping of Au metal precursors & - & 110 & 207 & 73.9 & - & [127] \\
\hline 2021 & Ternary design of P3HT & 0.008 & 30 & 265 & 44 & - & [128] \\
\hline 2021 & Ferric salt-doped P3HT & - & 20 & 128 & 85 & - & [129] \\
\hline 2021 & $\mathrm{~F}_{6} \mathrm{TCNNQ}$ doped $\mathrm{P} 3 \mathrm{HT}$ & - & 80 & 500 & 45 & - & [130] \\
\hline \multicolumn{8}{|c|}{ PEDOT: PSS } \\
\hline 2015 & Liquid exfoliated graphene doped PEDOT: PSS & 0.05 & 53.3 & 160 & $50-100$ & - & [131] \\
\hline 2016 & CNT/PEDOT: PSS nanocomposite films & - & $151 \pm 34$ & $780 \pm 51$ & $43.7 \pm 3.3$ & - & [55] \\
\hline 2016 & Te-PEDOT: PSS composites & 0.42 & 284 & 334.68 & 10.35 & - & [132] \\
\hline 2017 & PEDOT: PSS/PANI-CSA multilayer & - & 325 & 1680 & 44 & - & [133] \\
\hline 2018 & Solvent-treated PEDOT: PSS thin films & - & 245.58 & 1000 & 334.68 & - & [134] \\
\hline 2018 & Post-treatment of CNT/PEDOT: PSS & - & $83.2 \pm 6.4$ & - & $29.3 \pm 2.1$ & - & [135] \\
\hline 2019 & PEDOT: PSS-coated Te nanorod & 0.42 & 141.9 & 83.27 & 204.6 & - & [136] \\
\hline 2020 & Wet spun PEDOT: PSS & 0.1 & 30 & 830 & 19 & - & [137] \\
\hline 2020 & PEDOT: PSS film by treatment with hydrazine & 0.25 & 93.5 & - & 42.7 & - & [138] \\
\hline 2021 & Acid-treatment of PEDOT: PSS/Carbon Dots & 0.02 & $148.27 \pm 20$ & 1753.92 & - & - & [139] \\
\hline 2021 & PEDOT: PSS/Cu ${ }_{2} \mathrm{Se}$-based composite films & 0.4 & 820 & 470 & 78.2 & - & [140] \\
\hline 2021 & PEDOT: PSS/PVA/Te ternary composite fibers & - & 8.5 & 382.4 & 18 & - & [141] \\
\hline 2021 & PEDOT: PSS/SWCNT composites & - & $182.7 \pm 9.2$ & $1602.6 \pm 103$ & $33.4 \pm 0.4$ & - & [142] \\
\hline 2021 & PEDOT: PSS/Te nano-composite & 0.355 & $154.2 \pm 3$ & 240 & $95.3 \pm 3$ & 0.12 & [143] \\
\hline 2021 & PEDOT: PSS/Carbon Dots & - & $148.27 \pm 20$ & $1753.92 \pm 50$ & 30 & 0.38 & [139] \\
\hline 2021 & PEDOT: PSS films DMSO treatment & - & 105.2 & 578 & 67 & - & [144] \\
\hline
\end{tabular}


PANI

2015 PANI/graphene nanocomposite

2016 SWNTs/PANI composite

$2018 \quad \mathrm{TiO}_{2} /$ CNT/PANI composites

2018 PANI/Te nanorod

2019 PANI/GO nanocomposite

2021 PANI-coated $\mathrm{Ag}_{2}$ Se nanowire

2021 PANI/MOF

$2021 \quad \mathrm{PANI} / \mathrm{Bi}_{2} \mathrm{~S}_{3}$ hybrid

2021 Carbon nanotubes/polyaniline

2021 Carbon nanotubes/polyaniline

\begin{tabular}{llllll}
- & 55 & 814 & 26 & - & {$[145]$} \\
- & 51 & 1022 & 64 & - & {$[146]$} \\
- & 114.5 & 2183 & 22.9 & - & {$[147]$} \\
- & 52.9 & 0.32 & 264 & - & {$[148]$} \\
$0.4(\mathrm{RT})$ & 52.11 & 1489 & 59 & - & {$[149]$} \\
$0.8(363 \mathrm{~K})$ & & & & - & {$[150]$} \\
- & 320 & 301.9 & 98 & - & {$[151]$} \\
- & - & 0.01 & 66.6 & 0.0177 & {$[152]$} \\
0.06 & - & $13-21$ & 267 & - & {$[46]$} \\
- & 407 & 2235 & 42.7 & - & {$[153]$} \\
\hline- & $321 \pm 24$ & $3572 \pm 78$ & 33.3 & - &
\end{tabular}

SWCNT: Single-walled carbon nanotubes; P3HT: poly(3-hexylthiophene); CNT: carbon nanotube; F4TCNQ: 2,3,5,6-Tetrafluoro-7,7,8,8-tetracyanoquinodimethane; PEDOT: PSS: poly(3,4ethylenedioxythiophene)poly(styrenesulfonate); PANI: polyaniline; DMSO: dimethyl sulfoxide.

wristband-type devices. The maximum open-circuit voltage and current reached $336 \mathrm{mV}$ at a $\Delta T$ of $80 \mathrm{~K}$, revealing the possibility of PPy as a core material in wearable devices ${ }^{[187]}$.

\section{PANI}

PANI is a rod-shaped flexible organic material and has attracted significant attention since the 1980s. Chemical or electrochemical methods are widely used to synthesize PAN ${ }^{[188]}$. PANI is difficult to degrade, and it can be doped and de-doped easily by treatment with aqueous acid and base. The chemical reaction in PANI can be expressed as:

$n \mathrm{C}_{6} \mathrm{H}_{5} \mathrm{NH}_{2}+[\mathrm{O}] \rightarrow\left[\mathrm{C}_{6} \mathrm{H}_{4} \mathrm{NH}\right]_{n}+\mathrm{H}_{2} \mathrm{O}$

where $[\mathrm{O}]$ is a universal oxidant. The synthesis of PANI is facile, but the reaction mechanism is complicated ${ }^{[189]}$. Regarding the TE applications of PANI, recent works mainly focus on the hybrid materials composed of CNTs and PANI and the hybridization of inorganic materials and PANI. For example, an outstanding PANI-based material composed of SWCNT and PANI was reported in $2018^{[190]}$. The maximum $S^{2} \sigma$ can reach $100 \mu \mathrm{W} \mathrm{m}^{-1} \mathrm{~K}^{-2}$ with an ultra-high $\sigma$ of $4000 \mathrm{~S} \mathrm{~cm}^{-1}$ at $410 \mathrm{~K}$, which is the highest value until now. Figure $6 \mathrm{~A}$ illustrates the fabrication of PANI/SWCNT hybrids. A typical solution-based synthesis route with a drop-casting method was developed to prepare the flexible thin films. With the increase of CNTs, the film thickness was increased. Figure $6 \mathrm{~B}$ is the SEM image of the cross-section view of the thin film with $90 \mathrm{wt} \%$ SWCNT. When the content of SWCNTs was $<10 \mathrm{wt} \%$, some independent SWCNTs or nanotube clusters were isolated by the polymer coating, which affected the connection between SWCNTs and in turn $\sigma$. However, when the content was at 10- 
Table 3. Performance of flexible thermoelectric devices

\begin{tabular}{|c|c|c|c|c|c|c|c|c|c|}
\hline \multirow{2}{*}{ Year } & \multicolumn{2}{|c|}{ Materials } & \multirow{2}{*}{ - Substrate } & \multirow{2}{*}{ Couple number } & \multirow{2}{*}{$\Delta T(\mathrm{~K})$} & \multirow{2}{*}{ Output voltage (mV) } & \multirow{2}{*}{ Output power $(\mu \mathrm{W})$} & \multirow{2}{*}{ Power density $\left(\mu \mathbf{W} \mathrm{cm}^{-2}\right)$} & \multirow{2}{*}{ Ref. } \\
\hline & p-type & n-type & & & & & & & \\
\hline 2014 & Glass fabric $+\mathrm{Sb}_{2} \mathrm{Te}_{3}$ & Glass fabric $+\mathrm{Bi}_{2} \mathrm{Te}_{3}$ & $\mathrm{Al}_{2} \mathrm{O}_{3}$ & 8 & 50 & 80 & - & 3800 & [154] \\
\hline 2014 & $\mathrm{PI}+\mathrm{Sb}_{2} \mathrm{Te}_{3}$ & $\mathrm{Pl}+\mathrm{Bi}_{2} \mathrm{Te}_{3}$ & $\mathrm{Pl}$ & 7 & 50 & 80 & 1200 & - & [155] \\
\hline 2014 & SWNT/PVDF/DMF composites & SWNT composites & Glass & - & 50 & 0.9 & 0.6 & - & [156] \\
\hline 2015 & CNT/P3HT nanocomposite & - & $\mathrm{Pl}$ & - & 10 & 3 & 0.0327 & - & [122] \\
\hline 2015 & PEDOT: PSS & $\mathrm{Cu}$ intercalated $\mathrm{Bi}_{2} \mathrm{Se}_{3} /$ PVDF & Glass & - & 15 & 1.3 & - & 1222 & [157] \\
\hline 2015 & $\mathrm{Bi}_{0.5} \mathrm{Sb}_{1.5} \mathrm{Te}_{3}$ & $\mathrm{Bi}_{2} \mathrm{Te}_{2.7} \mathrm{Se}_{0.3}$ & $\mathrm{Pl}$ & - & 100 & 220 & 0.08 & - & [158] \\
\hline 2016 & $\mathrm{Sb}_{2} \mathrm{Te}_{3}$ & $\mathrm{Bi}_{2} \mathrm{Te}_{3}$ & Silk & 12 & 35 & 10 & 0.015 & - & [159] \\
\hline 2016 & $(0.25 \mathrm{Bi}, 0.75 \mathrm{Sb})_{2}(0.95 \mathrm{Te}, 0.05 \mathrm{Se})_{3}$ & $(0.98 \mathrm{Bi}, 0.02 \mathrm{Sb})_{2}(0.9 \mathrm{Te}, 0.1 \mathrm{Se})_{3}$ & PEN & 12 & 295.65 & 22.1 & 0.0022 & 55000 & {$[160]$} \\
\hline 2016 & $\mathrm{Bi} / \mathrm{Te}+\mathrm{CNTs}$ & $\mathrm{Bi} / \mathrm{Te}+\mathrm{CNTs}$ & PDMS & - & 333.15 & 920 & 0.57 & 4.5 & [161] \\
\hline 2016 & $\mathrm{NbSe}_{2}$ & $\mathrm{WS}_{2}$ & PDMS & - & 60 & - & 0.038 & - & [162] \\
\hline 2016 & $\mathrm{Bi}_{2} \mathrm{Te}_{3}+\mathrm{FPCB}$ & $\mathrm{Bi}_{2} \mathrm{Te}_{3}+\mathrm{FPCB}$ & $\mathrm{FPCB}$ & - & 12 & 48 & 0.1306 & 0.67 & [163] \\
\hline 2017 & NWPU/PEDOT: PSS/MWCNT & NWPU/N-doped MWCT & 3D fabric & 2 & 66 & 0.8 & 0.0026 & - & {$[164]$} \\
\hline 2017 & $\mathrm{Bi}_{0.5} \mathrm{Sb}_{1.5} \mathrm{Te}_{3}$ & $\mathrm{Bi}_{2} \mathrm{Se}_{0.5} \mathrm{Te}_{2.5}$ & PI & 1 & 35 & 10.5 & 23 & 4.75 & [165] \\
\hline 2017 & $\mathrm{Bi}_{0.5} \mathrm{Sb}_{1.5} \mathrm{Te}_{3}$ & $\mathrm{Bi}_{2} \mathrm{Te}_{3} / \mathrm{ZrB}_{2}$ & $\mathrm{PI}$ & 45 & 10 & 80 & 0.027 & - & [166] \\
\hline 2018 & $\mathrm{Bi}_{2} \mathrm{Te}_{3}$ & $\mathrm{Bi}_{2} \mathrm{Te}_{3}$ & FPCB & 52 & 50 & 37.2 & 0.18 & 16.8 & [167] \\
\hline 2018 & $\mathrm{Bi}_{0.5} \mathrm{Sb}_{1.5} \mathrm{Te}_{3}$ & $\mathrm{Bi}_{2} \mathrm{Se}_{0.5} \mathrm{Te}_{2.5}$ & FPCB/PDMS & 52 & 18 & 1600 & 2.4 & 13 & [168] \\
\hline 2019 & PEDOT-Cl & Carbon fiber thread & Cotton fabrics & 13 & 24 & 48.9 & 0.6935 & - & [169] \\
\hline 2019 & CNTs and $\mathrm{FeCl}_{3}$ & Polyethyleneimine/CNT & Glass & 5 & 50 & 23 & 0.008 & - & {$[170]$} \\
\hline 2020 & $\mathrm{Sb}_{2} \mathrm{Te}_{3}$ & $\mathrm{Bi}_{2} \mathrm{Te}_{2.7} \mathrm{Se}_{0.3}$ & $\mathrm{Pl}$ & 10 & - & 151 & 2.9 & 3.44 & [171] \\
\hline 2020 & $\mathrm{Bi}_{0.5} \mathrm{Sb}_{1.5} \mathrm{Te}_{3}$ & $\mathrm{Bi}_{2} \mathrm{Te}_{2.8} \mathrm{Se}_{0.2}$ & $\mathrm{PI}$ & - & 287.15 & 70 & 0.23 & 3.5 & [172] \\
\hline 2020 & $\mathrm{Sb}_{2} \mathrm{Te}_{3}$ & $\mathrm{Bi}_{2} \mathrm{Te}_{3}$ & $\mathrm{PI}$ & 36 & 20 & 79 & 0.0079 & - & [173] \\
\hline 2021 & $\mathrm{FeCl}_{3}$-doped P3HT & Silver paste & - & - & 23.3 & - & 0.00464 & - & [129] \\
\hline 2021 & PANI & $\mathrm{Ag}_{2} \mathrm{Se}$ & PVDF & - & 30 & 7.9 & 0.835 & 0.0233 & [150] \\
\hline 2021 & $\mathrm{Bi}_{0.4} \mathrm{Sb}_{1.6} \mathrm{Te}_{3}$ & $\mathrm{Ag}_{2} \mathrm{Se}$ & $\mathrm{Pl}$ & 13 & 40 & 11.5 & 0.25 & 0.0008 & [174] \\
\hline 2021 & $\mathrm{Bi}_{0.5} \mathrm{Sb}_{1.5} \mathrm{Te}_{3}$ & $\mathrm{Bi}_{2} \mathrm{Se}_{0.3} \mathrm{Te}_{2.7}$ & Glass & 4 & - & - & - & 35 & [175] \\
\hline
\end{tabular}

PVDF: Polyvinylidene fluoride; CNTs: carbon nanotubes; P3HT: poly(3-hexylthiophene); PEDOT: PSS: poly(3,4-ethylenedioxythiophene)poly(styrenesulfonate); FPCB: flexible printed circuit board; PANI: polyaniline; PDMS: polydimethyl siloxane; PI: polyimide; PEN: polyethylene naphthalate.

$90 \mathrm{wt} \%, \sigma$ was significantly increased since $\sigma$ was dominated by the three-dimensional interconnect structure of SWCNTs, as illustrated by Figure $6 \mathrm{C}$. After 100 manual bends, $S$ and $\sigma$ values were kept stable [Figure $6 \mathrm{D}$ ]. When the reaction time is $12 \mathrm{~h}, S^{2} \sigma$ reaches the maximum value of $\sim 2 \mu \mathrm{W}$ m ${ }^{-1} \mathrm{~K}^{-2}$, as shown in 

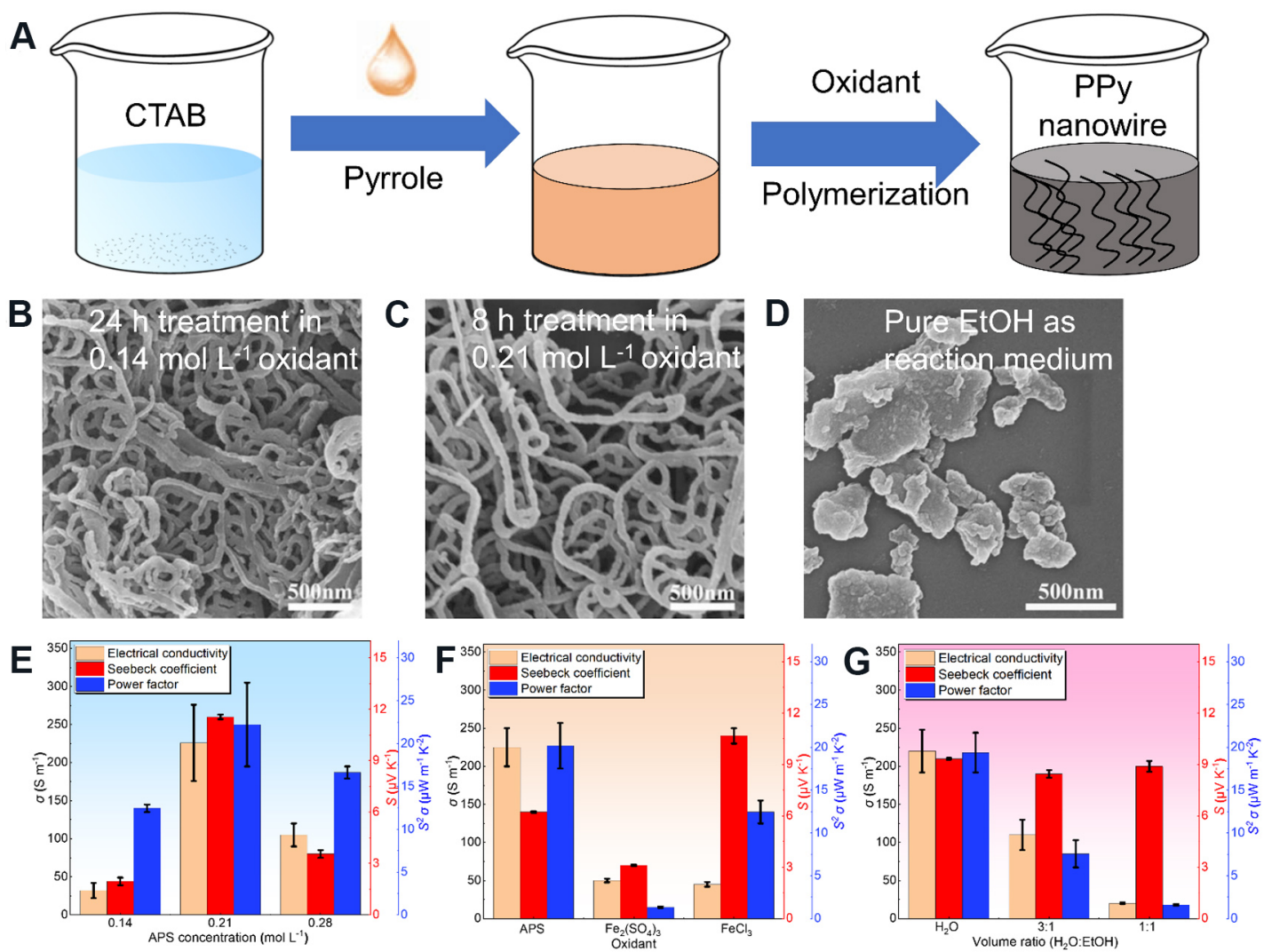

Figure 5. (A) Schematic illustration of the preparation process of PPy nanostructures by chemical oxidation polymerization; FESEM images of (B) products treated with oxidant concentration at $0.14 \mathrm{~mol} \mathrm{~L}^{-1}$ for $24 \mathrm{~h}$; (C) Products treated with oxidant concentration at $0.21 \mathrm{~mol} \mathrm{~L}^{-1}$ for $8 \mathrm{~h}$; (D) PPy prepared in pure EtOH; TE properties of $\sigma, S$, and $\mathrm{S}^{2} \sigma$ of PPy nanowires prepared with (E) a polymerization time of $8 \mathrm{~h}$ under different APS concentrations, (F) different oxidants, and (G) in various reaction media. Reproduced with permission ${ }^{[182]}$. Copyright 2017 Royal Society of Chemistry. PPy: Polypyrrole; APS: ammonium peroxydisulfate; TE: thermoelectric.

Figure $6 \mathrm{E}$. Figure $6 \mathrm{~F}-\mathrm{G}$ shows the TE performance as a function of the CNT content. All TE properties show the best values at $\sim 60 \mathrm{wt} \%$ SWCNTs, indicating that a rational design of SWCNT content is crucial for improving the TE performance of PANI. The output voltage can reach $0.047 \mu \mathrm{W}$ at a $\Delta T$ of $75 \mathrm{~K}$ in the asfabricated F-TEG.

Apart from the above case, there is SWCNT and sulfite-sulfonic acid-treated PANI. The strong interfacial interaction allowed PANI to grow regularly on the surface of SWCNT, leading to a ZT of 0.01 at room temperature ${ }^{[191]}$. Ethanol was used to treat PANI/SWCNT composites. The ethanol treatment allowed PANI to be partially de-doped, leading to significantly improved $S$. Although this treatment reduced $\sigma$ to some extent, there was also a high $S^{2} \sigma$ of $365 \mu \mathrm{W} \mathrm{m}{ }^{-1} \mathrm{~K}^{-2}$. In the developed device, the output power of $2.86 \mu \mathrm{W}$ was obtained at a $\Delta T$ of $50 \mathrm{~K}^{[47]}$. In addition to the cases of PANI/SWCNT, flexible three-dimensional graphene/PANI hybrid material was fabricated by a chemical vapor deposition method using a particulate nickel catalyst as support ${ }^{[192]}$, which showed excellent $\sigma, S$, and high flexibility during bending. After repeated bending tests, the maximum $S^{2} \sigma$ reached $81.9 \mu \mathrm{W} \mathrm{m}^{-1} \mathrm{~K}^{-2}$, which maintained more than $80 \%$ performance ${ }^{[192]}$.

\section{PEDOT}

PEDOT is a polymer-based 3,4-ethylenedioxythiophene (EDOT), which was first reported by Bayer AG in $1989^{[193]}$. Compared with other polythiophenes, PEDOT has optical transparency, high stability, medium 

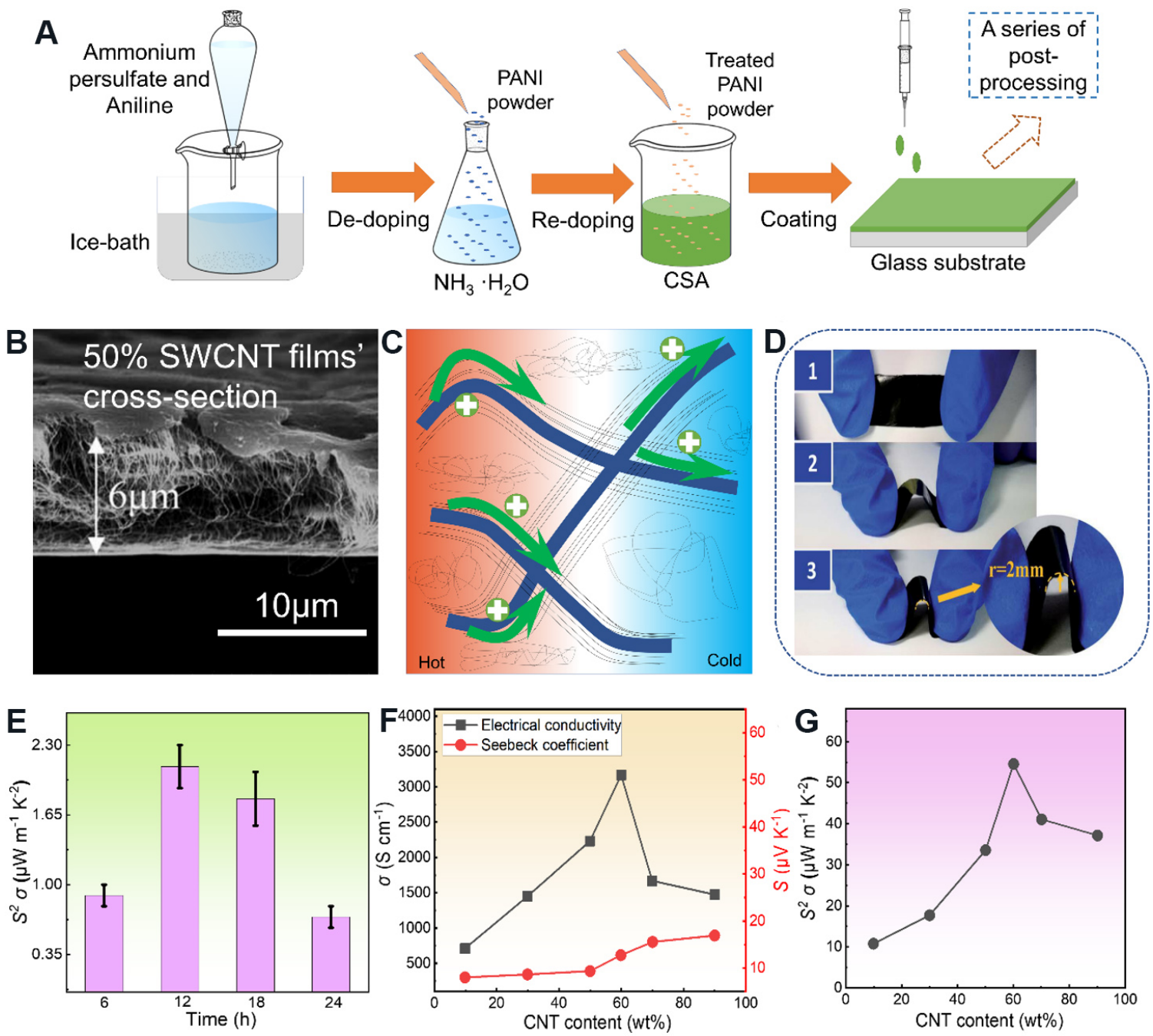

Figure 6. (A) Schematic diagram of the preparation of PANI film; (B) SEM cross-sectional image of the composite film with $90 \%$ SWCNT; (C) schematic diagram of electron transport of the composite film when the content of SWCNT is > $10 \%$; (D) illustrations of the bending experiment, the maximum bending radius are $r=2 \mathrm{~mm}$; (E) $S^{2} \sigma$ for different polymerization time; (F) $\sigma$ and $S$ and (G) $S^{2} \sigma$ as a function of the content of CNTs. Reproduced with permission ${ }^{[190]}$. Copyright 2018 Royal Society of Chemistry. PANI: Polyaniline; SWCNT: single-walled carbon nanotubes; CNTs: carbon nanotubes.

energy gap, low redox potential, and poor water solubility ${ }^{[194,195]}$. Therefore, PEDOT is usually used as a composite material to form PEDOT: PSS. This polymer is produced by oxidation, and the process starts with the formation of free radical cations $\left[\mathrm{C}_{2} \mathrm{H}_{4} \mathrm{O}_{2} \mathrm{C}_{4} \mathrm{H}_{2} \mathrm{~S}\right]^{+}$of the EDOT monomer. Thus, the ideal conversion with peroxodisulfate can be expressed as:

$n \mathrm{C}_{2} \mathrm{H}_{4} \mathrm{O}_{2} \mathrm{C}_{4} \mathrm{H}_{2} \mathrm{~S}+n\left(\mathrm{OSO}_{3}\right)_{2}{ }^{2-} \rightarrow\left[\mathrm{C}_{2} \mathrm{H}_{4} \mathrm{O}_{2} \mathrm{C}_{4} \mathrm{~S}\right]_{n}+2 n \mathrm{HOSO}_{3}$

Regarding the application of PEDOT in thermoelectrics, PEDOT shows many advantages, including good forming ability by versatile fabrication techniques, superior optical transparency in visible light range, high electrical conductivity and intrinsically high work function, and good physical and chemical stability in the air ${ }^{[196]}$. PEDOT was reported to be used in coated textiles ${ }^{[197]}$, prepared by a vapor phase polymerization technique. Three different types of fabrics, including cotton thread (CO), cotton textile (CT), and model textile (MT), were used to evaluate the performance. As shown in SEM images in Figure 7A-C, the 
A
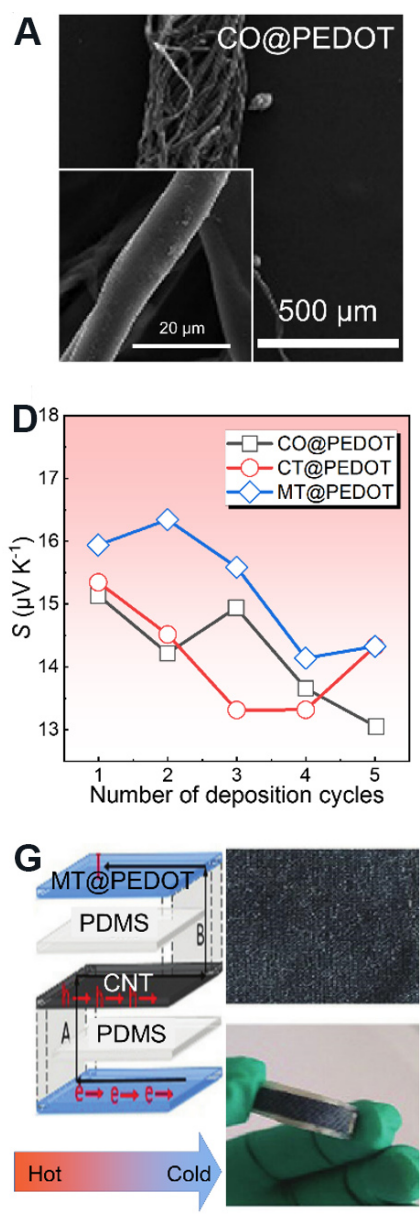

B

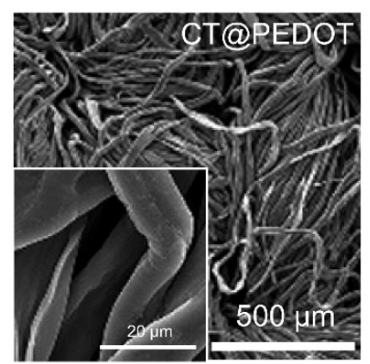

E

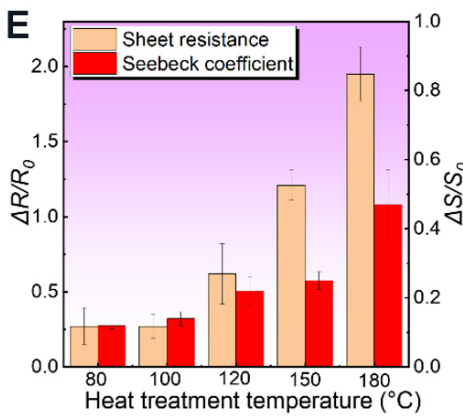

$\mathrm{H}$

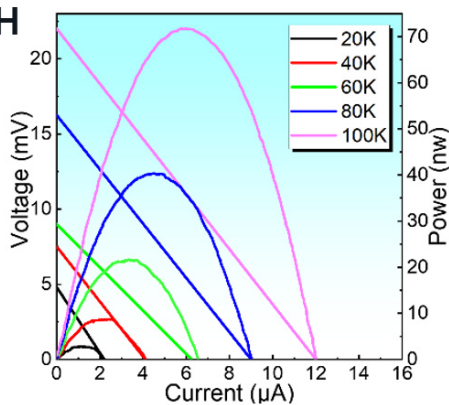

C
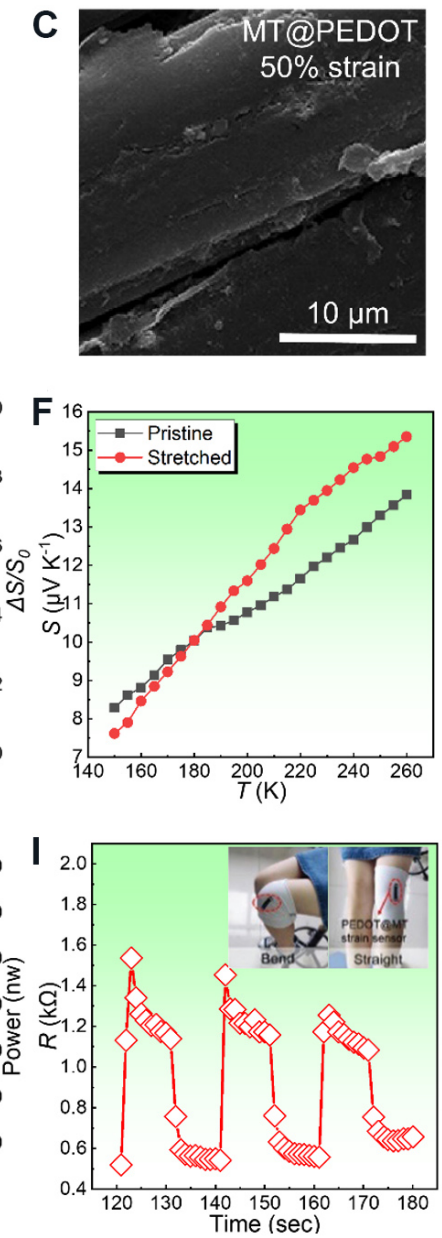

Figure 7. SEM images of (A) cotton thread (CO)-based; (B) cotton textile (CT)-based; and (C) model textile (MT)-based PEDOT; (D) the $S$ of the hybrids as a function of the number of deposition cycle; $(E)$ resistance change $\left(\Delta R / R_{0}\right)$ and $S$ change $\left(\Delta S / S_{0}\right)$ with different heat treatment temperatures; (F) temperature-dependent $S$ of pristine and stretched material; $(G)$ schematic diagram of the asfabricated F-TEG and the photos showing its size and surface; $(\mathrm{H})$ the performance of the F-TEG, and $(\mathrm{I})$ the resistance and time when the device is bent and straight. Reproduced with permission ${ }^{[197]}$. Copyright 2019 Royal Society of Chemistry.

regularity and surface characteristics of MT are better than the CO and CT. In the un-extended state, PEDOT polymerizes uniformly and neatly on the textile surface. When the stretch rate reaches $30 \%$, there are only some micro-cracks, and when the stretch rate reaches 50\%, PEDOT partially peels off, and the electron transport may be slightly affected. Figure 7D indicates the variation of $S$ for three different types of fabric in different deposition cycles. The value of $S$ fluctuates between $13-16 \mu \mathrm{V} \mathrm{K}{ }^{-1}$, but the value is influenced by the number of deposition. The stability of $S$ and resistance $(R)$ of the as-fabricated materials based on different heat treatment temperatures are shown in Figure 7E, in which the stability of $R$ and $S$ based on the MT-type PEDOT fabric is acceptable at low heat treatment temperatures. Figure $7 \mathrm{~F}$ shows temperature-dependent $S$ of pristine and stretched materials, from which $S$ increases with increasing the temperature for both pristine and stretched MT fabric. Figure $7 \mathrm{G}$ shows the schematic diagram of the asfabricated F-TEG and the photos showing its size and surface, from which high flexibility can be observed. Figure $7 \mathrm{H}$ shows its output voltage and power. An output voltage of $>20 \mathrm{mV}$, as well as an output power of $\sim 0.07 \mu \mathrm{W}$, can be achieved at a $\Delta T$ of $100 \mathrm{~K}$. By wearing the device on the knee, the resistance changes when the knee is bent and upright, from which the device exhibits considerable repeatability in a certain period [Figure 7I]. 
Recently, an ultra-fine PEDOT was fabricated using a homemade micellar soft-template method ${ }^{[198]}$ with a high $\sigma$ value of $1340 \mathrm{~S} \mathrm{~cm}^{-1}$ obtained. After treatment with $\mathrm{NaOH}$ and $\mathrm{H}_{2} \mathrm{SO}_{4}, \mathrm{~S}^{2} \sigma$ reached $46.51 \mu \mathrm{W} \mathrm{m}^{-1} \mathrm{~K}^{-2}$ at room temperature. Compared with the traditional preparation methods, the performance was improved by $54 \%$. After connecting six strips in series, the output power can reach $0.157 \mu \mathrm{W}$ at a $\Delta T$ of $51.6 \mathrm{~K}$, indicating that the film made by PEDOT nanowire has the potential to be employed in wearable devices. Moreover, controlled template-free in-situ polymerization of PEDOT was also studied to enhance the TE performance of the textile sublayer ${ }^{[199]}$. A simple one-bath template-free solution method was reported to fabricate PEDOT with an $\sigma$ value of up to $560 \mathrm{~S} \mathrm{~cm}^{-1}$ and an $S^{2} \sigma$ value of $0.9 \mu \mathrm{W} \mathrm{m} \mathrm{m}^{-1} \mathrm{~K}^{-2}$ at room temperature. Currently, the giant photo-magneto-TE effect was used to optimize the PEDOT grown orientation. It is worth noting that tosylate was synthesized using monomer seeds that were complexed through pyridine units to $3 \mathrm{D}$ tectons on graphene via surface-confined host-guest chemistry. At $300 \mathrm{~K}$ environment, EPG which was PEDOT:Tos coated by ZnPc:EDOT-Py/lean-mix concrete type of material (TSB)/unmodified graphene showed a great TE performance with $S^{2} \sigma=0.00115 \mu \mathrm{W} \mathrm{m}{ }^{-1} \mathrm{~K}^{-2}$ and $Z T=0.35^{[200]}$.

\section{PEDOT: PSS}

PEDOT: PSS is a polymer composed of two ionomers. One is sulfonated polystyrene, and the other one is PEDOT. PEDOT: PSS can be obtained by mixing an aqueous solution of PSS with EDOT monomers and then adding $\mathrm{Na}_{2} \mathrm{~S}_{2} \mathrm{O}_{8}$ and $\mathrm{Fe}_{2}\left(\mathrm{SO}_{4}\right)_{3}$ solution ${ }^{[201,202]}$. In terms of applying PEDOT: PSS as TE materials, rational pre- and post-treatments were commonly used to boost the TE performance of PEDOT: PSS. A triple post-treatment was developed to achieve an extraordinary TE performance in PEDOT: PSS thin films ${ }^{[203]}$, as illustrated in Figure 8. Figure 8A shows the XRD results for PEDOT: PSS films with different treating conditions, including treating with $\mathrm{CH}_{3} \mathrm{NO}, \mathrm{CH}_{3} \mathrm{NO}+\mathrm{H}_{2} \mathrm{SO}_{4}$, and $\mathrm{CH}_{3} \mathrm{NO}+\mathrm{H}_{2} \mathrm{SO}_{4}+\mathrm{NaBH}_{4}$, respectively. As can be seen, the peak values of PEDOT: PSS vary for different processing methods. Compared with the original sample, the intensity of (100) diffraction peak is significantly increased after treating with $\mathrm{H}_{2} \mathrm{SO}_{4}$, indicating significantly improved order in the as-fabricated thin films, as illustrated by the embedded figure in Figure $8 \mathrm{~A}$. Figure $8 \mathrm{~B}$ shows the XPS results of the thin films with different treatments. After the treatment with $\mathrm{CH}_{3} \mathrm{NO}$ and $\mathrm{H}_{2} \mathrm{SO}_{4}$, the mass ratio between PSS and PEDOT decreased, indicating that the rational post-treatment can achieve the selective removal of the PSS content in the film. Therefore, it can be concluded that the decrease in binding energy changes the average oxidation level. Figure $8 \mathrm{C}$ is the SEM image of the as-fabricated thin films after different treatments. After removing excess PSS, the cross-section shows an increasingly ordered microstructure. After the triple post-processing, the $\sigma$ can be significantly improved up to $1786 \mathrm{~S} \mathrm{~cm}^{-1}$, and $S$ can reach $28.1 \mu \mathrm{V} \mathrm{K}^{-1}$ at room temperature. The corresponding F-TEG using polyimide as substrate and copper wire as electrodes and n-type legs showed the maximum power density measured was $1 \mu \mathrm{W} \mathrm{cm}$ when the device was attached to the human arm.

In addition to employ $\mathrm{CH}_{3} \mathrm{NO}, \mathrm{H}_{2} \mathrm{SO}_{4}$, and $\mathrm{NaBH}_{4}$ as treatment, ethylene glycol (EG) pretreatment, $\mathrm{H}_{2} \mathrm{SO}_{4}$ post-treatment, and tetrakis(dimethylamino)ethylene (TDAE) post-treatment were also employed in PEDOT: PSS in sequence ${ }^{[60]} . \sigma$ can reach about $1333 \mathrm{~S} \mathrm{~cm}^{-1}$ after EG pre-treatment, mainly due to the damping caused by the excessive non-ionized PSS in the film. The post-processing of $\mathrm{H}_{2} \mathrm{SO}_{4}$ can further boost $\sigma$ up to $4000 \mathrm{~S} \mathrm{~cm}^{-1}$ since $\mathrm{H}_{2} \mathrm{SO}_{4}$ can order the microstructure of PEDOT: PSS. After coupling with TDAE treatment, a maximum $S^{2} \sigma$ of $37.2 \mu \mathrm{W} \mathrm{\textrm {m } ^ { - 1 }} \mathrm{K}^{-2}$ can be achieved [Figure 8D]. The as-fabricated device was designed according to the principle of the solar absorber and used the heat provided by solar energy to form a temperature gradient at both sides of the device, thereby leading to a high output power density. Figure $8 \mathrm{E}$ is a conceptual diagram of this device. In the actual test, the hot side was heated by solar energy to $356 \mathrm{~K}$ while the cold side maintained a temperature of about $300 \mathrm{~K}$. Therefore, based on the thermodynamic numerical analysis, the power density of a $20 \mu \mathrm{m}$ thick film can reach $5.12 \mu \mathrm{W} \mathrm{cm}$ at a $\Delta T$ of $56 \mathrm{~K}$. Figure $8 \mathrm{~F}$ is the relationship diagram of output voltage, power density and current, which fully embodies the application potential of the optimized films. 

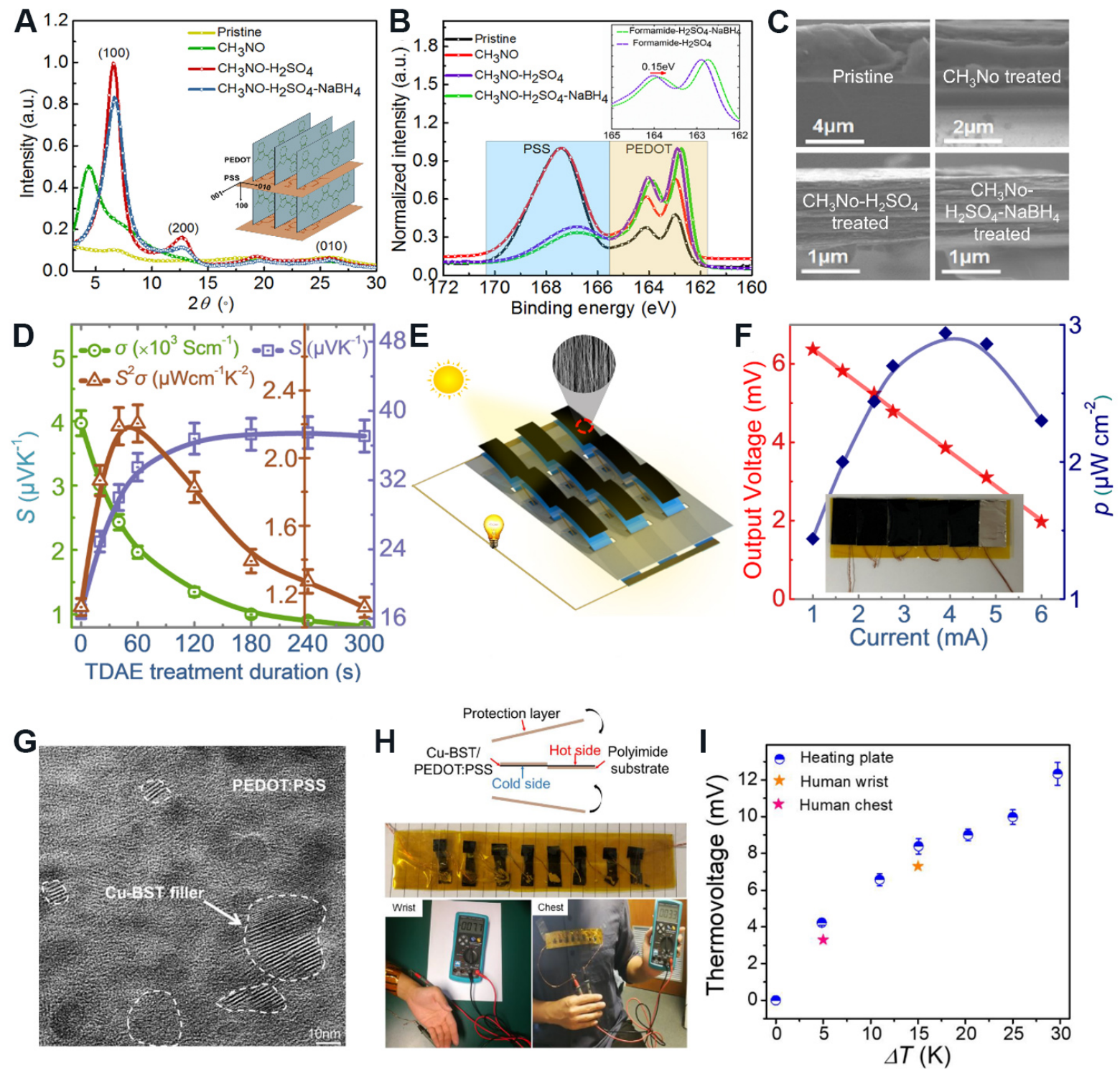

Figure 8. (A) XRD results for PEDOT: PSS films with different treating conditions within schematic diagram of PEDOT: PSS; (B) XPS results of PEDOT: PSS film with different treating conditions; (C) SEM images of cross-sectional PEDOT: PSS thin films after different treatments. Reproduced with permission ${ }^{[203]}$. Copyright 2019 ACS Publications. (D) Measured $\sigma, S$, and $S^{2} \sigma$ of tetrakis(dimethylamino)ethylene (TDAE)-treated PEDOT: PSS after different treatment durations; (E) Schematic diagram of the flexible TE module fabricated by PEDOT: PSS; (F) output power density and voltage as a function of the current. Reproduced with permission ${ }^{[60]}$. Copyright 2020 Royal Society of Chemistry. (G) TEM image of PEDOT: PSS films with 6 wt $\%$ Cu-Bi $\mathrm{Bi}_{0.5} \mathrm{Sb}_{1.5} \mathrm{Te}_{3}$ filler incorporation; $(\mathrm{H})$ images of the as-fabricated F-TE, and its thermovolta2021/9/29ge generations with human wrist and chest as thermal sources; (I) measured thermovoltage using a heating plate, human wrist, and chest as thermal sources. Reproduced with permission ${ }^{[204]}$. Copyright 2020 ELSEVIER. PEDOT: PSS: Poly(3,4-ethylenedioxythiophene)poly(styrenesulfonate).

In addition to pure PEDOT: PSS thin films, the hybrids of organic and inorganic materials have improved TE performance. For example, a thin-film material with high crystallinity was obtained by combining $\mathrm{Bi}_{0.5} \mathrm{Sb}_{1.5} \mathrm{Te}_{3}$ (BST) and PEDOT: PSS ${ }^{[204]}$. Figure $8 \mathrm{G}$ is a TEM image of BST-modified PEDOT: PSS. As can be seen, the protruding part is Cu-BST fillers, which were encapsulated by PSS. Such a unique structure is beneficial to improve the interface carrier transportation of the hybrid material. The initial PEDOT: PSS was processed with $\mathrm{H}_{2} \mathrm{SO}_{4}$, and a $\sigma$ of $1815 \mathrm{~S} \mathrm{~cm}^{-1}$ was obtained, which proved the improvement of TE performance by the aforementioned post-treatment ${ }^{[203]}$. After adding BST, $\sigma$ is reduced because BST scatters 

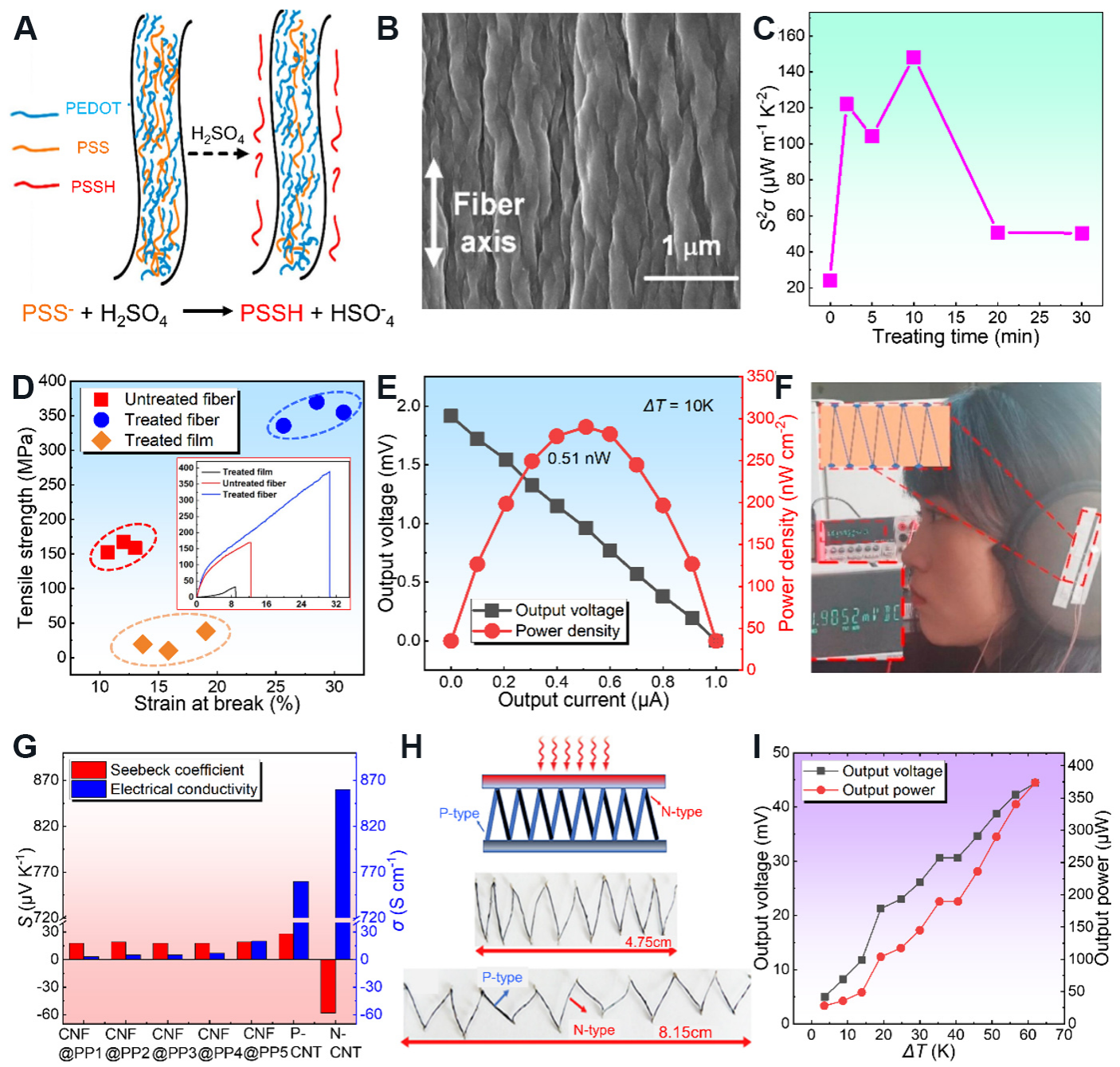

Figure 9. (A) Schematic diagram of PEDOT: PSS fiber treated by $\mathrm{H}_{2} \mathrm{SO}_{4} ;$ (B) Partially enlarged SEM image of PEDOT: PSS fiber; (C) Effect of $\mathrm{H}_{2} \mathrm{SO}_{4}$ treating time on the $\mathrm{S}^{2} \sigma$ fiber; (D) Evaluation of mechanical properties of PEDOT: PSS fiber and film by post-treatment; (E) Performance of fiber-based F-TEG under a $\Delta T$ of $10 \mathrm{~K}$; (F) Practical application of the fiber-based device. Reproduced with permission ${ }^{[205]}$. Copyright 2020 ELSEVIER. (G) S and $\sigma$ of fiber-based materials with different contents of cotton fiber; $(\mathrm{H})$ schematic diagram and photos of the as-fabricated device, and (I) Relationship between device performance and $\Delta T$. Reproduced with permission ${ }^{[207]}$. Copyright 2020 ELSEVIER. PEDOT: PSS: Poly(3,4-ethylenedioxythiophene)poly(styrenesulfonate); F-TEG: flexible TE generator.

the carrier, which reduces the mobility and, in turn, suppresses $\sigma$. However, with increasing the Cu content, $\sigma$ was rapidly increased up to $2520 \mathrm{~S} \mathrm{~cm}^{-1}$ with a Cu-BST content of $0.1 \mathrm{wt} \%$. Interestingly, Cu-BST has a higher $S$ than BST fillers. This may cause by introduced CuTe layers reducing interfacial contact resistance, allowing more carriers to transport through BST fillers to induce sufficient interfacial energy filtering. In terms of the device, Figure $8 \mathrm{H}$ shows its schematic diagram, physical photo, and test of the flexible device. Such a device can realize power generation with a $\Delta T$ of 5-30 K, and the peak power generation can reach $12.3 \mathrm{mV}$ at a $\Delta T$ of $30 \mathrm{~K}$ [Figure $8 \mathrm{I}]$.

In addition to studies of PEDOT: PSS films, one-dimensional PEDOT: PSS fibers are also widely reported. By using a continuous wet spinning process and treating with sulfuric acid, the TE performance of the PEDOT: PSS fibers can be optimized ${ }^{[205]}$. Figure 9A shows a schematic diagram of the separation of PSS in the fiber during $\mathrm{H}_{2} \mathrm{SO}_{4}$ treatment. Figure $9 \mathrm{~B}$ is a partially enlarged SEM image after $\mathrm{H}_{2} \mathrm{SO}_{4}$ treatment. As can 
be seen, the microscopic morphology of the fiber shows inapparent change before and after the $\mathrm{H}_{2} \mathrm{SO}_{4}$ treatment. However, the diameter decreases obviously because the PSS in the fiber is partially removed. The observed $S^{2} \sigma$ value is directly related to the processing time of $\mathrm{H}_{2} \mathrm{SO}_{4}$ [Figure $9 \mathrm{C}$ ]. When $\mathrm{H}_{2} \mathrm{SO}_{4}$ was processed for $10 \mathrm{~min}, S^{2} \sigma$ reached its maximum value. Besides, a standard tensile test was employed to evaluate the mechanical properties of PEDOT: PSS fibers and the results are shown in Figure 9D. As can be seen, the mechanical properties of the post-treated PEDOT: PSS fibers are better than those of the untreated fibers, and the mechanical properties of the untreated fibers are better than that of the treated film material. Figure $9 \mathrm{E}$ shows the measured performance of a device composed of 5 pairs of $\mathrm{p}$ (PEDOT: PSS)-n(Ni) junctions. The maximum output power can reach $0.0051 \mu \mathrm{W}$ at a $\Delta T$ of $10 \mathrm{~K}$. Figure $9 \mathrm{~F}$ is the stitching of the device to the earphone. When $\Delta T$ is $\sim 9.1 \mathrm{~K}$, the maximum power density can reach $0.273 \mu \mathrm{W} \mathrm{cm}{ }^{-2}$, which is comparable to the performance of $\mathrm{Bi}_{2} \mathrm{Te}_{3}$-based materials ${ }^{[206]}$. A novel F-TEG can be designed on cotton fibers using PEDOT: PSS as p-type materials and CNTs as n-type materials ${ }^{[207]}$. Figure $9 \mathrm{G}$ is the comparison of $\sigma$ and $S$ of materials with different cotton fiber content. The largest $\sigma$ can reach $871 \mathrm{~S} \mathrm{~cm}^{-1}$, and $S$ can reach $58 \mu \mathrm{V} \mathrm{K}^{-1}$. Figure $9 \mathrm{H}$ is the schematic diagram and photos of the device. Figure $9 \mathrm{I}$ illustrates the output power can reach $380 \mu \mathrm{W}$ at a $\Delta T$ of $60 \mathrm{~K}$. Combing CNT and PEDOT: PSS ${ }^{[135]}$ using wet-spinning and post-processing, the resulted $\mathrm{p}$ - and n-type $S^{2} \sigma$ can reach $83.2 \pm 6.4$ and $113 \pm 25 \mu \mathrm{W} \mathrm{m}^{-1} \mathrm{~K}^{-2}$, respectively. When 12 pairs of $\mathrm{p}$ - and n-type fibers were used to make a device, the maximum output power can be observed at $430 \mu \mathrm{W}$ at a $\Delta T$ of $10 \mathrm{~K}$, suggesting that the PEDOT: PSS fibers to be employed in wearable electronics.

\section{P3HT}

$\mathrm{P} 3 \mathrm{HT}$ is a 3-hexylthiophene polymer derived from polythiophenes. $\mathrm{P} 3 \mathrm{HT}$ is a colored solid and easily soluble in organic solvents. P3HT was first synthesized in the $1980 \mathrm{~s}^{[208]}$. There are various synthetic methods to fabricate $\mathrm{P} 3 \mathrm{HT}$, including electropolymerization, oxidation (mainly by $\mathrm{FeCl}_{3}$ ), nickel catalysis (McCullough, Rieke, GRIM), Pd catalysis (Suzuki and Stille coupling), and recent direct arylation Aggregation (DArP $)^{[209]}$.

Research on the thermoelectricity of $\mathrm{P} 3 \mathrm{HT}$ was almost relevant to F4TCNQ doping. For example, it was reported that by doping $\mathrm{F} 4 \mathrm{CNQ}$ into $\mathrm{P} 3 \mathrm{HT}$ through a vapor phase infiltration, its TE performance was improved $^{[210]}$. Figure $10 \mathrm{~A}$ shows the schematic diagram of the vapor phase doping method and the chemical structures of $\mathrm{P} 3 \mathrm{HT}$ and F4TCNQ. Based on morphology, doping can make the material exhibit better conductivity under the same doping concentration. Similarly, in the solution doping, P3HT and F4CNQ are aggregated due to charge transfer, which directly affects the different morphologies in the film. Therefore, some products have poor structural domains at the same doping level, resulting in differences in $\sigma$. Regarding the specific content, the $\sigma$ value by vapor phase doping was 48 times higher than that of the solution doping. In terms of the achieved $S$ and $\sigma$, they can reach $85 \mu \mathrm{V} \mathrm{K}^{-1}$ and $10 \mathrm{~S} \mathrm{~cm}^{-1}$ in vapor-doped P3HT. In contrast, by solution doping, the $S$ is $100 \mu \mathrm{V} \mathrm{K}^{-1}$, but the $\sigma$ is only $10^{-5}-10^{-3} \mathrm{~S} \mathrm{~cm}^{-1[210]}$. As shown in Figure $10 \mathrm{~B}$, the $S^{2} \sigma$ by vapor phase doping is much better than solution doping. In addition to this case, plenty of studies have been using F4CNQ as a dopant for P3HT. For example, the influences of controlling chain alignment and crystallization on $S^{2} \sigma$ of $\mathrm{P} 3 \mathrm{HT}$ were reported with F4CNQ as the dopant ${ }^{[126]}$. Higher inplane orientation and higher doping concentration can lead to the semi-crystalline structure of aligned $\mathrm{P} 3 \mathrm{HT}$, which contributes to better TE performance than the smectic-like phase. The highest $\sigma$ can reach $160 \mathrm{~S} \mathrm{~cm}^{-1}$, and $S^{2} \sigma$ can reach $56 \mu \mathrm{W} \mathrm{m} \mathrm{m}^{-1} \mathrm{~K}^{-2}$. Similarly, another work reported using vapor phase doping to improve the TE performance of $\mathrm{P}_{3} \mathrm{HT}^{[124]}$. By distributing the $\mathrm{F} 4 \mathrm{CNQ}$ dopants into P3HT, the semicrystalline nanostructure has a pronounced influence on the charge-carrier mobility, which results in both improved $n$ and $\mu$, leading to $\sigma$ of $>10 \mathrm{~S} \mathrm{~cm}^{-1}$ with a high $S$ of $40-60 \mu \mathrm{V} \mathrm{K}^{-1}$. As a result of the highest degree crystal, $S^{2} \sigma$ reaches $3 \mu \mathrm{W} \mathrm{m}{ }^{-1} \mathrm{~K}^{-2}$ at room temperature. Another ${ }^{[25]}$ reported that the best TE performance in $\mathrm{P} 3 \mathrm{HT}$ can be achieved by doping with $17 \mathrm{wt} \% \mathrm{~F} 4 \mathrm{CNQ}$, attributed to the fact that the dopant at this 

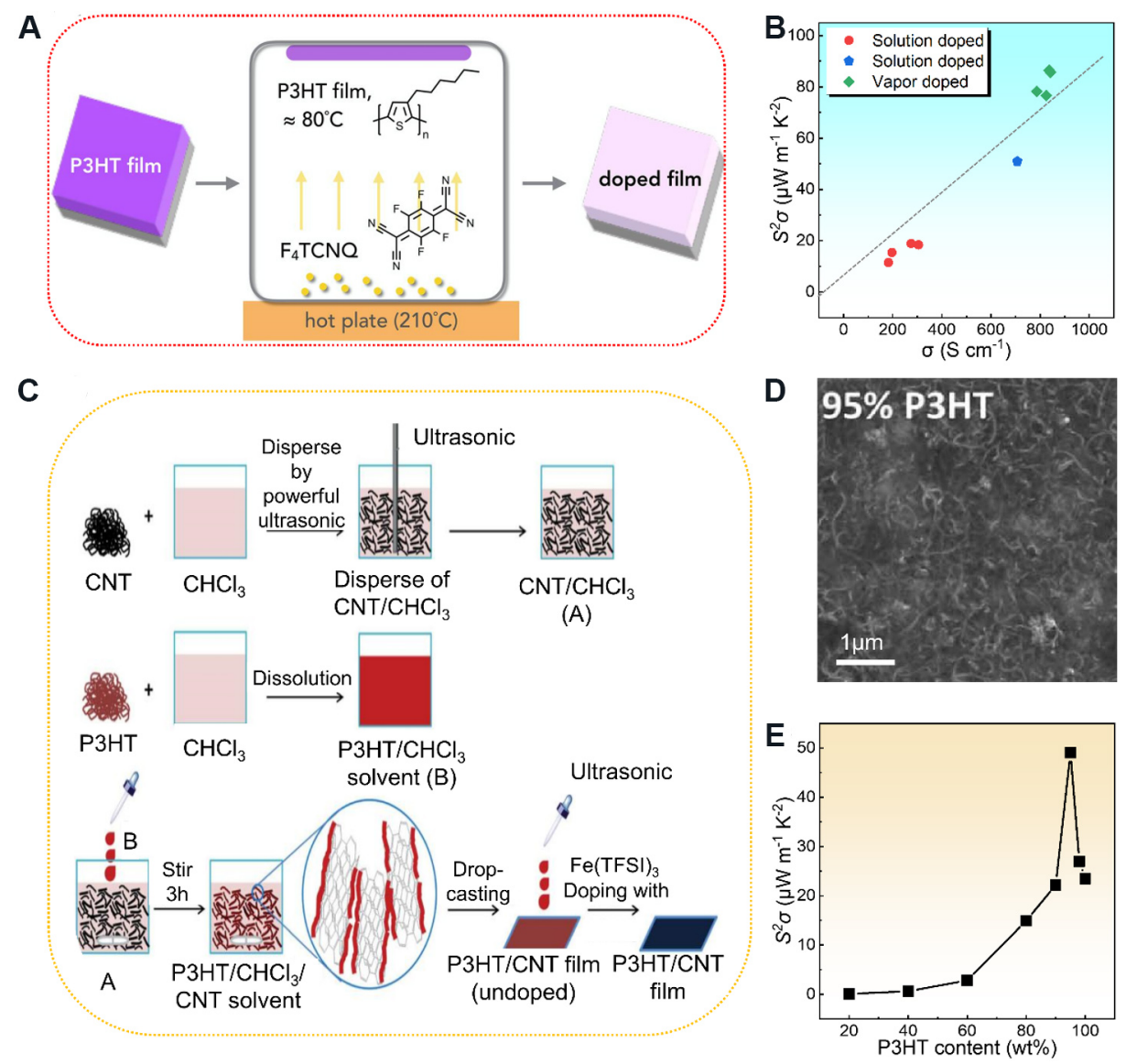

Figure 10. (A) Schematic diagram of the vapor phase doping method and the chemical structures of P3HT and F4CNQ; (B) comparison of TE performance between vapor phase doping and solution doping for P3HT. Reproduced with permission ${ }^{[210]}$. Copyright 2018 ACS Publications. (C) Schematic diagram of the synthesis of the P3HT/CNT composite film composed of CNTs with different diameters and different contents; (D) SEM image of the hybrid film with $95 \mathrm{wt} \% \mathrm{P} 3 \mathrm{HT}$; (E) $\mathrm{S}^{2} \sigma$ of the hybrid film as a function of P3HT content. Reproduced with permission ${ }^{[211]}$. Copyright 2018 The Royal Society of Chemistry. P3HT: Poly(3-hexylthiophene); CNTs: carbon nanotubes.

concentration can form a good distribution matrix. There was not much dopant remaining in the polymer film to cause phase separation. If the dopant is excessive, the value of $\sigma$ can be reduced. The highest $\sigma$ obtained was $1.6 \mathrm{~S} \mathrm{~cm}^{-1}$, and $S$ and $S^{2} \sigma$ were $102 \mu \mathrm{V} \mathrm{K}^{-1}$ and $1.6 \mu \mathrm{W} \mathrm{m} \mathrm{m}^{-1}$, respectively.

In addition to the research on F4CNQ-doped $\mathrm{P} 3 \mathrm{HT}, \mathrm{CNT} / \mathrm{P} 3 \mathrm{HT}$ composite materials are also in popularity ${ }^{[211]}$, from which the good performance is benefitted from the unique structure and excellent electron transport performance of CNT itself. For example, composite films with different diameters were prepared [Figure 10C]. As a result, $40 \mathrm{wt} \%$ of CNTs were reported to be uniformly dispersed in the composite material, but the optimal TE performance was not achieved. Regarding the selection of the diameter of CNTs, the diameter of CNTs of $<15 \mathrm{~nm}$ was the best, and the maximum $\sigma$ can reach $36.2 \mathrm{~S} \mathrm{~cm}^{-1}$. When P3HT reached 95-98 wt\%, CNTs were uniformly and compactly dispersed inside the structure [Figure 10D]. In terms of TE performance, $95 \mathrm{wt} \% \mathrm{P} 3 \mathrm{HT}$ was better than the other concentrations. As a result, the peak $\sigma$ was $579 \mathrm{~S} \mathrm{~cm}^{-1}$, and the best $S^{2} \sigma$ reached $50 \mu \mathrm{W} \mathrm{m}^{-1} \mathrm{~K}^{-2}$ at $95 \mathrm{wt} \%$ [Figure $10 \mathrm{E}$ ]. 


\section{Other conducting polymers}

In addition to PPy, PANI, PEDOT, PEDOT: PSS, and P3HT, other conducting polymers such as polyvinylidene fluoride (PVDF), Poly $\left[\mathrm{K}_{x}\right.$ (nickel-ethylenetetrathiolate)], and polystyrene (PS) are also reported to have potential research possibilities. For example, PVDF can compound with $\mathrm{Ag}_{2} \mathrm{Se}$ nanowires to form a free-standing composite film ${ }^{[212]}$. Figure $11 \mathrm{~A}$ shows a typical preparation processing. Figure $11 \mathrm{~B}$ is an SEM image of the fabricated composite film, in which a grape-like structure can be seen. Its TE performance is shown in Figure $11 \mathrm{C}$. At $300 \mathrm{~K}, S^{2} \sigma$ can reach $189.02 \mu \mathrm{W} \mathrm{m}{ }^{-1} \mathrm{~K}^{-2}$, and ZT reached 0.008. After 1000 bending cycles, the conductivity only drops by $15.8 \%$ [Figure $11 \mathrm{D}$ ] due to the entanglement of the two materials in the structure. Figure $11 \mathrm{E}$ is the as-fabricated F-TEG assembled with five sets of products where the joints are made of copper foil and silver. Figure $11 \mathrm{~F}$ shows the device's performance. When the temperature was increased, the resistance significantly dropped, and the output power continued to rise, reaching the maximum value at $30 \mathrm{~K}$. An output power of $0.005 \mu \mathrm{W}$ can be obtained ${ }^{[212]}$. In addition to compounding with $\mathrm{Ag}_{2} \mathrm{Se}$, a study about $\mathrm{Bi}_{2} \mathrm{Se}_{3} / \mathrm{PVDF}$ composite was reported ${ }^{[213]}$. $\kappa$ of this composite was significantly lower than that of $\mathrm{Bi}_{2} \mathrm{Se}_{3}$, which was only $0.06 \mathrm{~W} \mathrm{~m}^{-1} \mathrm{~K}^{-1}$ at $300 \mathrm{~K}$, and the $Z T$ value was $\sim 0.004$.

In addition to the research on PVDF-based TE materials, the TE potential of PS was also studied ${ }^{[214]}$. PS was used to realize the condensation of the CNT conductive network as a binder to maintain the microstructure of the material. Compared with pure CNT, the film made of PS exhibited higher $\sigma$ and $S^{2} \sigma$. When the CNT concentration reaches $75 \%, S^{2} \sigma$ can reach $789 \mu \mathrm{W} \mathrm{m}{ }^{-1} \mathrm{~K}^{-2}$. Similar research reported that a device made of PS-based TE materials could show an output power density of $5.5 \mu \mathrm{W} \mathrm{cm}{ }^{-2}$ under a $\Delta T$ of $70 \mathrm{~K}^{[215]}$. Another popular TE polymer with great research value is the Poly $\left[\mathrm{K}_{x}\right.$ (nickel-ethylenetetrathiolate)]. This type of $\mathrm{n}$ type material based on nickel and polyurethane has been widely studied in recent years. For example, an ntype composite film can withstand $50 \%$ of the deformation, and its $S$ was about $40 \mu \mathrm{V} \mathrm{K}{ }^{-1}$ with a $\sigma$ of $\sim 0.01 \mathrm{~S} \mathrm{~cm}^{-1[216]}$. When mixing metal, this type of material still has good mechanical ductility and processing properties. In an 18-legs connected TE device, an output power of $0.468 \mu \mathrm{W}$ and a power density of $577.8 \mu \mathrm{W} \mathrm{cm}{ }^{-2}$ was obtained at a $\Delta T$ of $12 \mathrm{~K}^{[217]}$.

\section{CONCLUSION, CHALLENGES, AND OUTLOOK}

Organic TE materials show good flexibility and promising TE performance. Therefore, many different types of conducting polymer-based TE materials, including PPy, PANI, P3HT, PEDOT, and their hybrid/composite materials based on metal-organic complexes, are investigated. Among them, PANI and PEDOT: PSS show very high $\sigma$ exceeding $4000 \mathrm{~S} \mathrm{~cm}^{-1}$, and their developed devices also show high power output. So far, the reported highest TE performance of conducting polymers was formed by the hybridization of PEDOT and $\mathrm{Bi}_{2} \mathrm{Te}_{3}$. This hybrid has an ultra-high $S^{2} \sigma$ with a value of $1350 \mu \mathrm{W} \mathrm{m} \mathrm{m}^{-1} \mathrm{~K}^{-2}$, and the $Z T$ gets up to 0.58 at room temperature ${ }^{[218]}$. As for the power density, one outstanding PEDOT: PSS was reported to have a value of $1200 \mu \mathrm{W} \mathrm{cm}{ }^{-2}$ at a $\Delta T$ of $50 \mathrm{~K}^{[155]}$.

According to the previous studies, a few challenges still exist in materials, devices, and test methods. In terms of material, the existing p-type conducting polymer-based TE materials still show limited TE properties compared to their inorganic counterparts, and the current strategies such as doping, hybridization/compositing, and post-treatment still show limited effects. Furthermore, the charge transport mechanisms are not clear, and the modeling is limited by the current technique. One significant shortage is that it is difficult to link the micro/nanostructure to their TE properties, especially for $\kappa$. Besides, the development of $n$-type conducting polymer-based TE materials is still challenging, and their TE performance is not stable enough. Other problems in materials are practical performance, such as their costs, stability, and flexibility, which are all challenges in the current applications. Regarding the devices, in addition to their poor performance, there is a lack of mature design rules for F-TEGs, such as the 

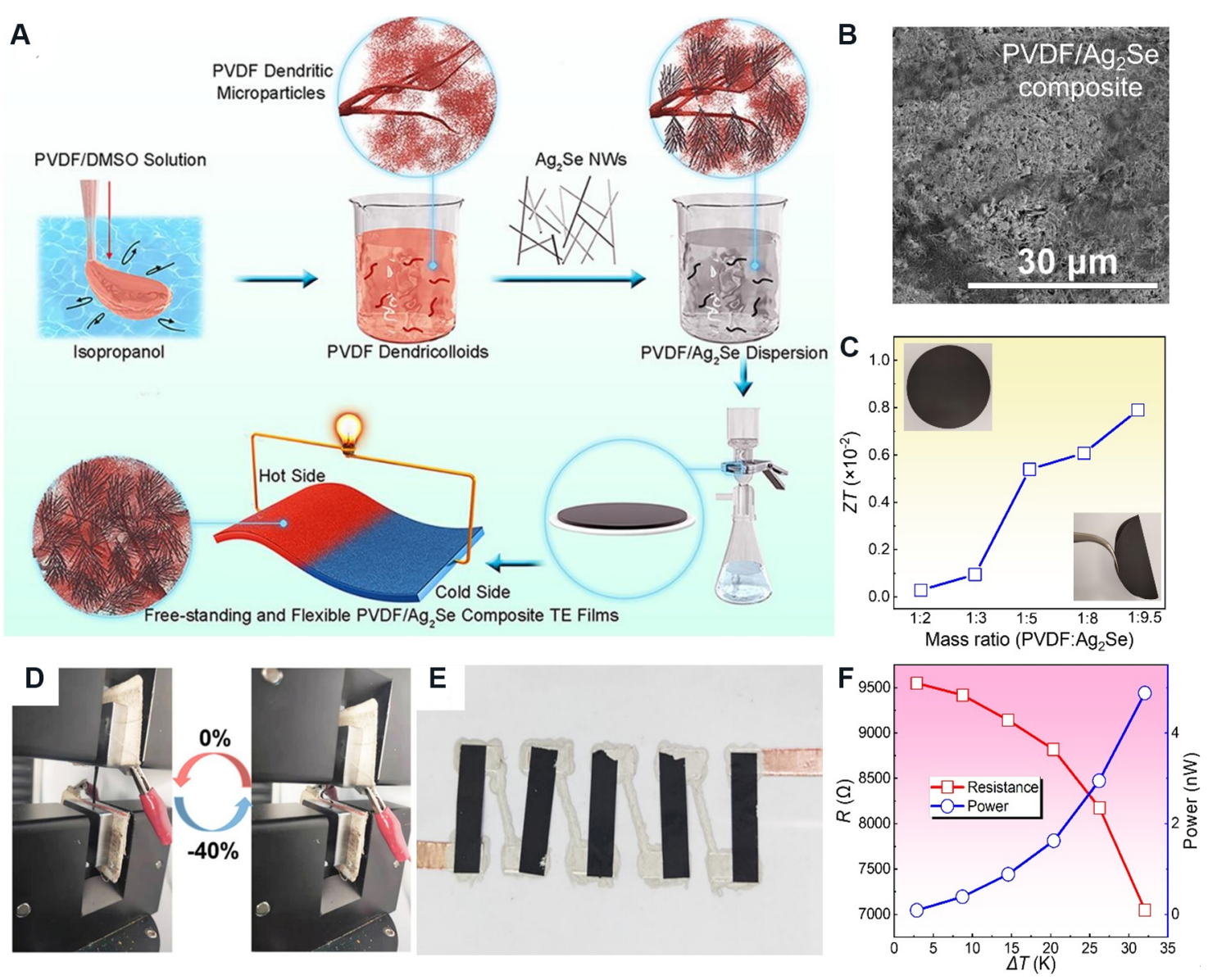

Figure 11. (A) Schematic diagram of the synthesis of PVDF/Ag 2 Se composite film; (B) partially enlarged SEM image of thin-film with 1:9.5 mass ratio of PVDF/ $\mathrm{Ag}_{2} \mathrm{Se}$; (C) schematic diagram of the relationship between $Z T$ and material mass ratio, the insets show the photos of the as-fabricated flexible films; (D) specific bending test of the film; (E) the as-fabricated device composed of 5 groups of PVDF/Ag 2 Se composite films; (F) corresponding device performance. Reproduced with permission ${ }^{[212]}$. Copyright 2020 ACS Publications. PVDF: Polyvinylidene fluoride.

topological design, suitable substrates, and electrodes, as well as their durability and comfortability when wearing by human skin. In terms of efficiency, all these parameters, including interface resistance, interface thermal resistance, material aggregation structure, bending, and folding, affect the performance of the device, but the evasion and optimization of these influencing factors still cannot find effective rules. Furthermore, in terms of the test methods, $\kappa$ of the conducting polymer-based TE materials is historically tricky due to the limitation of the evaluation technique. There is also a lack of computational-assisted methods to design conducting polymer-based devices since the current computation-based calculations such as first-principles and finite element analysis are mostly based on inorganic materials.

As illustrated in Figure 12, we further summarize the future outlooks in the field of conducting polymerbased TE materials and devices ${ }^{[219-223]}$.

\section{Boosting TE performance of conducting polymer-based materials}

For n-type materials, the optimization can generally start from molecule design, doping, and treatment methods. Molecule design is possible to induce the difference between molecule stacking and morphology. Rigid skeleton structure is a popular direction of current research, which is considered to optimize carrier transport ${ }^{[224-226]}$. Besides, the optimization of the skeleton can adjust the lowest energy unoccupied molecular 


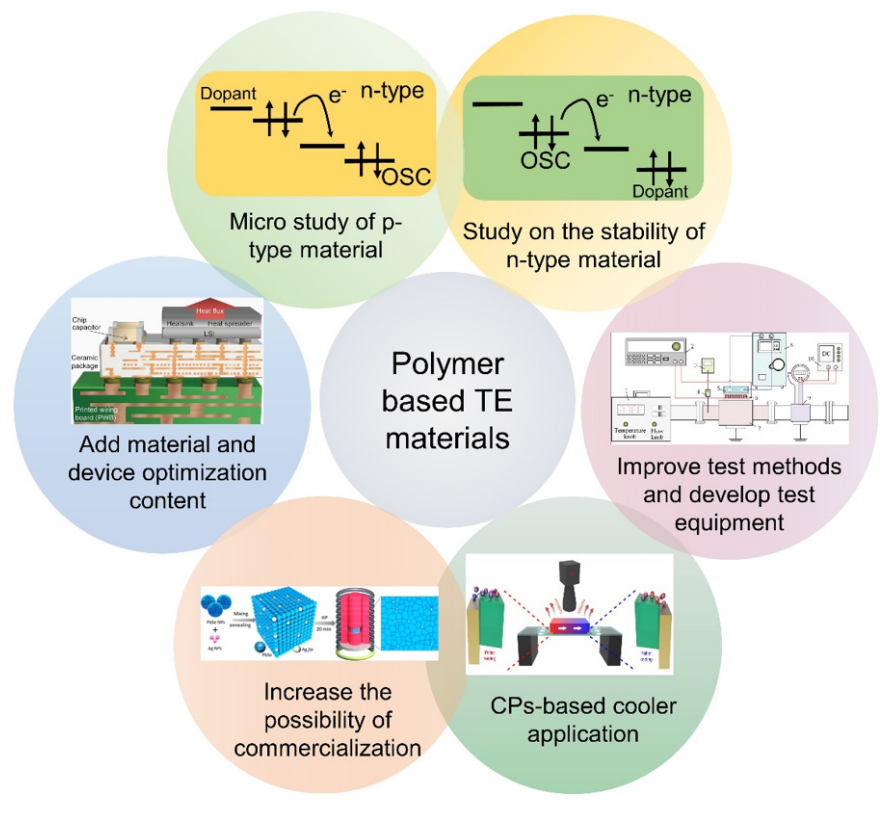

Figure 12. Strategies and outlooks for conducting polymer-based TE materials and devices. Optimization strategy. Reproduced with permission ${ }^{[219]}$. Copyright 2021 Nature Portfolio. Test equipment. Reproduced with permission ${ }^{[220]}$. Copyright 2020 ELSEVIER. Commercial TE devices. Reproduced with permission ${ }^{[221]}$. Copyright 2021 ACS Publications. p-type and n-type principles. Mechanism of Peltier effect and device geometry. Reproduced under the terms of the Creative Commons Attribution License (CC BY) ${ }^{[222]}$. Copyright 2021 frontiers. Cooler. Reproduced with permission ${ }^{[223]}$. Copyright 2018 Nature Portfolio. TE: Thermoelectric.

orbital energy level of the doping system, which improves the doping efficiency and stability ${ }^{[22]}$. It is also essential to develop more suitable dopants because the miscibility between the dopant and the host conducting polymers affects the structural arrangement of the matrix directly, as well as the degree of energy level matching ${ }^{[227,228]}$. The current processing method mainly relies on encapsulation, which is possible to improve the stability of the n-type conducting polymer materials. However, to realize further optimization of n-type conducting polymers, structure improvement and reasonable design are still significant. For p-type conducting polymers, the research at this stage is relatively mature. However, there are still possibilities to improve the TE performance of p-type conducting polymers, which benefitted from the development of the TE mechanism for conducting polymers. Similar to n-type, current research of ptype conducting polymers can still optimize from morphology ${ }^{[229]}$, doping level ${ }^{[230]}$, crystallinity ${ }^{[231]}$, and side chain $^{[232]}$.

\section{Improving the design of conducting polymers-based devices}

Generally, ZTs of conducting polymers determine the maximum performance of devices. However, the device structure also directly impacts the energy conversion efficiency. Therefore, future research can focus on device assembly, including serial, folding, and stacking routes. Usually, the performance is serial > folding $>$ stacking route ${ }^{[233]}$. Therefore, to maximize the device performance, selecting serial and increasing $\mathrm{p}-\mathrm{n}$ couple is inevitable. Moreover, the volume of the devices increases and affects the actual application seriously ${ }^{[234]}$. Therefore, to optimize the device performance, transplanting the construction methods such as $\mathrm{Y}_{\text {-type }}{ }^{[235]}$ or $\pi$-type ${ }^{[236]}$ can be extended the design of conducting polymers-based TE devices with high energy conversion efficiency.

\section{Developing the evaluation technique for conducting polymers-based materials and devices}

Because $Z T$ is determined by $S, \sigma$, and $\kappa$, it is crucial to develop a testing method to measure these parameters accurately. The four-point probe is mature for testing $\sigma$, while $S$ evaluation relies on temperature 
difference and the voltage difference between the two sides of the sample. Since most of the samples of conducting polymers are thin films, the process, morphology, and size seriously affect the accuracy of $\Delta T$ measurement. Otherwise, the high impedance brought by low conductivity is also a difficult problem for testing $S$. Therefore, exploiting new methods and instruments to precise $S$ is indispensable. For example, based on the Thomson effect, using an ac-dc technique to precise $S$ is an ideal method ${ }^{[237]}$. With regards to $\kappa$, there are standard steady-state absolute measurement ${ }^{[238]}$, Ångström method ${ }^{[239]}$, hot-strip (THS) $\operatorname{method}^{[240]}$, etc. However, current measurements are still difficult to limit the error to $5 \%$. Therefore, exploiting new methods to match different conducting polymers is the trend of development. As well, it is difficult to link the micro/nanostructures to the properties for conducting polymers. The studies of micro/nanostructures reveal the essence of boosting the performance of conducting polymers, such as the crystallinity that significantly affects the $\sigma$ and the micro/nanoscale imperfects or defects that greatly influence the $\kappa$. Developing advanced micro/nanoscale characterization techniques such as high-resolution electron scanning/transmission microscopies are potential ways to solve this issue.

\section{Commercialization of F-TEGs}

Wearable F-TEGs with high power generation can be used to charge wearable/portable electronics with low energy demand and the vehicle industry ${ }^{[241]}$. It should be noted that although the performance is still unsatisfactory for current F-TEGs that rely on conducting polymers, PEDOT: PSS has already exhibited great potential to meet the power supply for low-power electronical equipment. Furthermore, if F-TEGs with non-toxic and wear-resistant features can be made into wristbands or clothing to supply power for electronic watches or other portable electronic devices by absorbing human body heat, it will be a leap forward for the entire industry.

\section{Conducting polymers-based TE coolers}

Since the inadequate performance of current-conducting polymers, it is still difficult to apply conducting polymers on TE coolers. However, there is the cooler research about Poly(Ni-ett) with relatively high ZT $(\sim 0.3)^{[242]}$. With the analysis of infrared imaging technique, the maximum $\Delta T$ can be up to $41 \mathrm{~K}$ at the two contacts and cooling of $0.2 \mathrm{~K}$ even under heat-insulated conditions. According to the cooling coefficient of performance ${ }^{[243]}, Z T$ directly influences the efficiency of TE coolers. Therefore, this value is still the essential prerequisite for conducting polymers used in TE coolers, which is the critical content of future research.

\section{DECLARATIONS}

\section{Authors' contributions}

Made the literature review and drafted the original version: Cao T, Shi XL

Revised the manuscript: Chen ZG, Zou J

Conceived and supervised the project: Chen ZG

\section{Availability of data and materials}

Not applicable.

\section{Financial support and sponsorship}

This project was financially supported by the Australian Research Council and Innovation Centre for Sustainable Steel Project.

\section{Conflicts of interest}

All authors declared that there are no conflicts of interest. 


\section{Ethical approval and consent to participate}

Not applicable.

\section{Consent for publication}

Not applicable.

\section{Copyright}

(c) The Author(s) 2021.

\section{REFERENCES}

1. Shi XL, Zou J, Chen ZG. Advanced thermoelectric design: from materials and structures to devices. Chem Rev 2020;120:7399-515. DOI PubMed

2. Roychowdhury S, Ghosh T, Arora R, Samanta M, Xie L, et al. Enhanced atomic ordering leads to high thermoelectric performance in $\mathrm{AgSbTe}_{2}$. Science 2021;371:722-7. DOI PubMed

3. Zheng Y, Slade TJ, Hu L, et al. Defect engineering in thermoelectric materials: what have we learned? Chem Soc Rev 2021;50:902254. DOI PubMed

4. Jiang B, Yu Y, Cui J, et al. High-entropy-stabilized chalcogenides with high thermoelectric performance. Science 2021;371:830-4. DOI PubMed

5. Tan G, Zhao LD, Kanatzidis MG. Rationally designing high-performance bulk thermoelectric materials. Chem Rev 2016;116:1212349. DOI PubMed

6. Xu S, Shi XL, Dargusch M, Di C, Zou J, Chen ZG. Conducting polymer-based flexible thermoelectric materials and devices: from mechanisms to applications. Prog Mater Sci 2021;121:100840. DOI

7. Xiao Y, Zhao LD. Seeking new, highly effective thermoelectrics. Science 2020;367:1196-7. DOI PubMed

8. Shi X, Chen L. Thermoelectric materials step up. Nat Mater 2016;15:691-2. DOI PubMed

9. Snyder GJ, LeBlanc S, Crane D, et al. Distributed and localized cooling with thermoelectrics. Joule 2021;5:748-51. DOI

10. Wang Y, Yang L, Shi X, et al. Flexible thermoelectric materials and generators: challenges and innovations. Adv Mater 2019;31:1807916. DOI PubMed

11. Venkatasubramanian R, Siivola E, Colpitts T, O'Quinn B. Thin-film thermoelectric devices with high room-temperature figures of merit. Nature 2001;413:597-602. DOI PubMed

12. Bi Y, Yang Y, Shi XL, et al. Full-spectrum responsive photocatalytic activity via non-noble metal Bi decorated mulberry-like BiVO J Mater Sci Technol 2021;83:102-12. DOI

13. Du Y, Xu J, Paul B, Eklund P. Flexible thermoelectric materials and devices. Appl Mater Today 2018;12:366-88. DOI PubMed PMC

14. Hong M, Chen ZG, Pei Y, Yang L, Zou J. Limit of ZT enhancement in rocksalt structured chalcogenides by band convergence. Phys Rev $B$ 2016;94:161201. DOI

15. Wu H, Shi XL, Liu WD, et al. Double perovskite $\mathrm{Pr}_{2} \mathrm{CoFeO}_{6}$ thermoelectric oxide: roles of Sr-doping and Micro/nanostructuring. Chem Eng J 2021;425:130668. DOI

16. Shi XL, Wu H, Liu Q, et al. $\mathrm{SrTiO}_{3}$-based thermoelectrics: progress and challenges. Nano Energy 2020;78:105195. DOI

17. Moshwan R, Yang L, Zou J, Chen ZG. Eco-friendly SnTe thermoelectric materials: progress and future challenges. Adv Funct Mater 2017;27:1703278. DOI

18. Tian BZ, Jiang XP, Chen J, et al. Low lattice thermal conductivity and enhanced thermoelectric performance of SnTe via chemical electroless plating of Ag. Rare Metals :2021. DOI

19. Liu W, Shi X, Hong M, et al. Ag doping induced abnormal lattice thermal conductivity in $\mathrm{Cu}_{2}$ Se. J Mater Chem C 2018;6:13225-31. DOI

20. Shi XL, Tao X, Zou J, Chen ZG. High-performance thermoelectric SnSe: aqueous synthesis, innovations, and challenges. Adv Sci 2020;7:1902923. DOI PubMed PMC

21. Shi XL, Liu WD, Wu AY, et al. Optimization of sodium hydroxide for securing high thermoelectric performance in polycrystalline $\mathrm{Sn}_{1-\mathrm{x}}$ Se via anisotropy and vacancy synergy. InfoMat 2020;2:1201-15. DOI

22. Shi XL, Zheng K, Liu WD, et al. Realizing high thermoelectric performance in n-type highly distorted Sb-doped SnSe microplates via tuning high electron concentration and inducing intensive crystal defects. Adv Energy Mater 2018;8:1800775. DOI

23. Sun Y, Yang Y, Shi XL, et al. Self-standing film assembled using SnS-Sn/multiwalled carbon nanotubes encapsulated carbon fibers: a potential large-scale production material for ultra-stable Sodium-Ion battery anodes. ACS Appl Mater Interfaces 2021;13:28359-68. DOI PubMed

24. Zheng Y, Shi XL, Yuan H, et al. A synergy of strain loading and laser radiation in determining the high-performing electrical transports in the single Cu-doped SnSe microbelt. Mater Today Phys 2020;13:100198. DOI

25. Liu WD, Wang DZ, Liu Q, Zhou W, Shao Z, Chen CG. High-performance GeTe-based thermoelectrics: from materials to devices. Adv Energy Mater 2020;10:2000367. DOI

26. Hong M, Lyv W, Li M, et al. Rashba effect maximizes thermoelectric performance of GeTe derivatives. Joule 2020;4:2030-43. DOI

27. Hong M, Zheng K, Lyv W, et al. Computer-aided design of high-efficiency GeTe-based thermoelectric devices. Energy Environ Sci 
2020;13:1856-64. DOI

28. Hong M, Chen ZG, Yang L, et al. Realizing $\mathrm{zT}$ of 2.3 in $\mathrm{Ge}_{1-\mathrm{x}-\mathrm{y}} \mathrm{Sb}_{\mathrm{x}} \mathrm{In}_{\mathrm{y}} \mathrm{Te}$ via reducing the phase-transition temperature and introducing resonant energy doping. Adv Mater 2018;30:1705942. DOI PubMed

29. Tan P, Zou Y, Fan Y, Li Z. Self-powered wearable electronics. Wearable Technologies 2020;1:e5. DOI

30. Dargusch M, Liu WD, Chen ZG. Thermoelectric generators: alternative power supply for wearable electrocardiographic systems. $A d v$ Sci (Weinh) 2020;7:2001362. DOI PubMed PMC

31. Huang L, Lin S, Xu Z, et al. Fiber-based energy conversion devices for human-body energy harvesting. Adv Mater 2020;32:1902034. DOI PubMed

32. Pulidindi K, Pandey H. Conductive polymers market size, share and industry analysis report by conduction mechanism. Available from: https://www.gminsights.com/industry-analysis/conductive-polymers-market. [Last accessed on 28 Sep 2021].

33. Shi XL, Chen WY, Zhang T, Zou J, Chen ZG. Fiber-based thermoelectrics for solid, portable, and wearable electronics. Energy Environ Sci 2021;14:729-64. DOI

34. Chen WY, Shi XL, Zou J, Chen ZG. Wearable fiber-based thermoelectrics from materials to applications. Nano Energy 2020;81:105684. DOI

35. Meng W, Liu X, Song H, et al. Advances and challenges in 2D MXenes: from structures to energy storage and conversions. Nano Today 2021;40:101273. DOI

36. Siouane S, Jovanović S, Poure P. Equivalent electrical circuits of thermoelectric generators under different operating conditions. Energies 2017;10:386. DOI

37. Ji W, Shi XL, Liu WD, et al. Boosting the thermoelectric performance of n-type $\mathrm{Bi}_{2} \mathrm{~S}_{3}$ by hierarchical structure manipulation and carrier density optimization. Nano Energy 2021;87:106171. DOI

38. Deng Y, Gao X, Shi XL, et al. Graphene oxide and adiponectin-functionalized sulfonated poly(etheretherketone) with effective osteogenicity and remotely repeatable photodisinfection. Chem Mater 2020;32:2180-93. DOI

39. Debnath A, Deb K, Sarkar K, Saha B. Low interfacial energy barrier and improved thermoelectric performance in Te-incorporated polypyrrole. $J$ Phys Chem C 2021;125:168-77. DOI

40. Fan W, Zhang Y, Guo CY, Chen G. Toward high thermoelectric performance for polypyrrole composites by dynamic 3-phase interfacial electropolymerization and chemical doping of carbon nanotubes. Compos Sci Technol 2019;183:107794. DOI

41. Li C, Ma H, Tian Z. Thermoelectric properties of crystalline and amorphous polypyrrole: a computational study. Appl Therm Eng 2017;111:1441-7. DOI

42. Liang L, Chen G, Guo CY. Enhanced thermoelectric performance by self-assembled layered morphology of polypyrrole nanowire/single-walled carbon nanotube composites. Compos Sci Technol 2016;129:130-6. DOI

43. Xin S, Yang N, Gao F, Zhao J, Li L, Teng C. Free-standing and flexible polypyrrole nanotube/reduced graphene oxide hybrid film with promising thermoelectric performance. Mater Chem Phys 2018;212:440-5. DOI

44. Li H, Liang Y, Liu S, Qiao F, Li P, He C. Modulating carrier transport for the enhanced thermoelectric performance of carbon nanotubes/polyaniline composites. Org Electron 2019;69:62-8. DOI

45. Li H, Liu S, Li P, et al. Interfacial control and carrier tuning of carbon nanotube/polyaniline composites for high thermoelectric performance. Carbon 2018;136:292-8. DOI

46. Li H, Liu Y, Li P, Liu S, Du F, He C. Enhanced thermoelectric performance of carbon nanotubes/polyaniline composites by multiple interface engineering. ACS Appl Mater Interfaces 2021;13:6650-8. DOI PubMed

47. Li P, Zhao Y, Li H, et al. Facile green strategy for improving thermoelectric performance of carbon nanotube/polyaniline composites by ethanol treatment. Compos Sci Technol 2020;189:108023. DOI

48. Wang L, Yao Q, Xiao J, et al. Engineered molecular chain ordering in single-walled carbon nanotubes/polyaniline composite films for high-performance organic thermoelectric materials. Chem Asian J 2016;11:1804-10. DOI PubMed

49. Hong CT, Lee W, Kang YH, et al. Effective doping by spin-coating and enhanced thermoelectric power factors in SWCNT/P3HT hybrid films. J Mater Chem A 2015;3:12314-9. DOI

50. Li X, Zhu Z, Wang T, et al. Improved thermoelectric performance of P3HT/SWCNTs composite films by HClO4 post-treatment. Compos Commun 2019;12:128-32. DOI

51. Myint MTZ, Nishikawa T, Inoue H, Omoto K, Kyaw AKK, Hayashi Y. Improved room-temperature thermoelectric characteristics in F4TCNQ-doped CNT yarn/P3HT composite by controlled doping. Org Electron 2021;90:106056. DOI

52. Qu S, Yao Q, Shi W, Wang L, Chen L. The influence of molecular configuration on the thermoelectrical properties of poly(3hexylthiophene). J Electron Mater 2016;45:1389-96. DOI

53. Qu S, Yao Q, Yu B, et al. Optimizing the thermoelectric performance of poly(3-hexylthiophene) through molecular-weight engineering. Chem Asian J 2018;13:3246-53. DOI PubMed

54. Untilova V, Hynynen J, Hofmann AI, et al. High thermoelectric power factor of poly(3-hexylthiophene) through in-plane alignment and doping with a molybdenum dithiolene complex. Macromolecules 2020;53:6314-21. DOI PubMed PMC

55. Lee W, Kang YH, Lee JY, Jang KS, Cho SY. Improving the thermoelectric power factor of CNT/PEDOT:PSS nanocomposite films by ethylene glycol treatment. RSC Adv 2016;6:53339-44. DOI

56. Liu S, Li H, He C. Simultaneous enhancement of electrical conductivity and seebeck coefficient in organic thermoelectric SWNT/PEDOT:PSS nanocomposites. Carbon 2019;149:25-32. DOI

57. Stevens D, Gamage GA, Ren Z, Grunlan J. Salt doping to improve thermoelectric power factor of organic nanocomposite thin films. RSC Adv 2020;10:11800-7. DOI

58. Wang YY, Cai KF, Shen S, Yao X. In-situ fabrication and enhanced thermoelectric properties of carbon nanotubes filled poly $(3,4-$ 
ethylenedioxythiophene) composites. Synthetic Met 2015;209:480-3. DOI

59. Zhang L, Harima Y, Imae I. Highly improved thermoelectric performances of PEDOT:PSS/SWCNT composites by solvent treatment. Org Electron 2017;51:304-7. DOI

60. Xu S, Hong M, Shi XL, et al. Computation-guided design of high-performance flexible thermoelectric modules for sunlight-toelectricity conversion. Energy Environ Sci 2020;13:3480-8. DOI

61. Liu T, Chen J, Li M, et al. Achieving enhanced thermoelectric performance of $\mathrm{Ca}_{1-x-y} \mathrm{La}_{\mathrm{x}} \mathrm{Sr}_{\mathrm{y}} \mathrm{MnO}_{3}$ via synergistic carrier concentration optimization and chemical bond engineering. Chem Eng $J$ :2020.127364. DOI

62. He W, Zhang G, Zhang X, Ji J, Li G, Zhao X. Recent development and application of thermoelectric generator and cooler. Appl Energ 2015;143:1-25. DOI

63. Riffat SB, Ma X. Thermoelectrics: a review of present and potential applications. Appl Therm Eng 2003;23:913-35. DOI

64. Dai D, Zhou Y, Liu J. Liquid metal based thermoelectric generation system for waste heat recovery. Renew Energ 2011;36:3530-6. DOI

65. Tie SF, Tan CW. A review of energy sources and energy management system in electric vehicles. Renew Sust Energ Rev 2013;20:82102. DOI

66. Ullah KR, Saidur R, Ping HW, Akikur RK, Shuvo NH. A review of solar thermal refrigeration and cooling methods. Renew Sust Energ Rev 2013;24:499-513. DOI

67. Siddique ARM, Mahmud S, Heyst BV. A review of the state of the science on wearable thermoelectric power generators (TEGs) and their existing challenges. Renew Sust Energ Rev 2017;73:730-44. DOI

68. Bubnova O, Crispin X. Towards polymer-based organic thermoelectric generators. Energy Environ Sci 2012;5:9345-62. DOI

69. Mayer JM. Simple Marcus-theory-type model for hydrogen-atom transfer/proton-coupled electron transfer. J Phys Chem Lett 2011;2:1481-9. DOI PubMed PMC

70. Bao Z, Locklin JJ. Organic field-effect transistors. 1st ed. Boca Raton: CRC Press; 2007. DOI

71. Dimitrijev S. Principles of semiconductor devices. New York: Oxford University Press; 2006.

72. Nardes AM, Kemerink M, Janssen RAJ. Anisotropic hopping conduction in spin-coated PEDOT:PSS thin films. Phys Rev $B$ 2007;76:085208. DOI

73. Glaudell AM, Cochran JE, Patel SN, Chabinyc ML. Impact of the doping method on conductivity and thermopower in semiconducting polythiophenes. Adv Energy Mater 2015;5:1401072. DOI

74. Zhang Q, Sun Y, Qin Y, Xu W, Zhu D. Two soluble polymers with lower ionization potentials: doping and thermoelectric properties. J Mater Chem A 2016;4:1432-9. DOI

75. Mateeva N, Niculescu H, Schlenoff J, Testardi L. Correlation of seebeck coefficient and electric conductivity in polyaniline and polypyrrole. J Appl Phys 1998;83:3111-7. DOI

76. Stevens MP. Polymer chemistry. New York: Oxford University Press; 1990.

77. Zhang Y, Choi JR, Park SJ. Interlayer polymerization in amine-terminated macromolecular chain-grafted expanded graphite for fabricating highly thermal conductive and physically strong thermoset composites for thermal management applications. Compos Part A-appl S 2018;109:498-506. DOI

78. Zhang Y, Heo YJ, Son YR, et al. Recent advanced thermal interfacial materials: a review of conducting mechanisms and parameters of carbon materials. Carbon 2019;142:445-60. DOI

79. Li JF, Liu WS, Zhao LD, Zhou M. High-performance nanostructured thermoelectric materials. NPG Asia Mater 2010;2:152-8. DOI PubMed

80. Neamen DA. Semiconductor physics and devices: basic principles. Boston: Mass:McGraw-Hill; 2003.

81. Chen G, Zhu GH, Lee H, et al. Increased phonon scattering by nanograins and point defects in nanostructured silicon with a low concentration of germanium. Phys Rev Lett 2009;102:196803. DOI PubMed

82. Xu X, Zhou J, Chen J. Thermal transport in conductive polymer-based materials. Adv Funct Mater 2020;30:1904704. DOI

83. Dong L, Xi Q, Chen D, et al. Dimensional crossover of heat conduction in amorphous polyimide nanofibers. Natl Sci Rev 2018;5:500-6. DOI

84. Zhang T, Luo T. Role of chain morphology and stiffness in thermal conductivity of amorphous polymers. $J$ Phys Chem $B$ 2016;120:803-12. DOI PubMed

85. Krach A, Advani SG. Influence of void shape, void volume and matrix anisotropy on effective thermal conductivity of a three-phase composite. J Compos Mater 1996;30:933-46. DOI

86. He L. Improve thermal conductivity of polymer composites via conductive network. ES Materials \& Manufacturing 2021;13:1-2. DOI

87. Hone J, Whitney M, Piskoti C, Zettl A. Thermal conductivity of single-walled carbon nanotubes. Phys Rev B 1999;59:R2514-R6. DOI

88. Park T, Park C, Kim B, Shin H, Kim E. Flexible PEDOT electrodes with large thermoelectric power factors to generate electricity by the touch of fingertips. Energy Environ Sci 2013;6:788-92. DOI

89. Peierls RE. The momentum of light in a refracting medium. Proceedings of the Royal Society of London A Mathematical and Physical Sciences 1976;347:475-91. DOI

90. Huxtable ST. Heat transport in superlattices and nanowire arrays. Ann Arbor: ProQuest Dissertations Publishing; 2002.

91. Zhang L, Li X, Deng H, Jing Y, Fu Q. Enhanced thermal conductivity and electrical insulation properties of polymer composites via constructing Pglass/CNTs confined hybrid fillers. Compos Part A-appl S 2018;115:1-7. DOI

92. Oh H, Kim K, Ryu S, Kim J. Enhancement of thermal conductivity of polymethyl methacrylate-coated graphene/epoxy composites 
using admicellar polymerization with different ionic surfactants. Compos Part A-appl S 2019;116:206-15. DOI

93. Zhang Y, Heo YJ, Park M, Park SJ. Recent advances in organic thermoelectric materials: principle mechanisms and emerging carbon-based green energy materials. Polymers 2019;11:167. DOI PubMed PMC

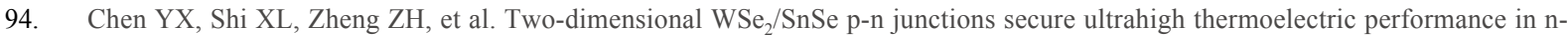
type Pb/I co-doped polycrystalline SnSe. Mater Today Phys 2021;16:100306. DOI

95. Saha B, Koh YR, Comparan J, et al. Cross-plane thermal conductivity of (Ti,W)N/(Al,Sc)N metal/semiconductor superlattices. Phys Rev B 2016;93:045311. DOI

96. Zhao W, Ding J, Zou Y, Di CA, Zhu D. Chemical doping of organic semiconductors for thermoelectric applications. Chem Soc Rev 2020;49:7210-28. DOI PubMed

97. Liang Z, Zhang Y, Souri M, et al. Influence of dopant size and electron affinity on the electrical conductivity and thermoelectric properties of a series of conjugated polymers. J Mater Chem A 2018;6:16495-505. DOI

98. Gao J, Roehling JD, Li Y, Guo H, Moulé AJ, Grey JK. The effect of 2,3,5,6-tetrafluoro-7,7,8,8-tetracyanoquinodimethane charge transfer dopants on the conformation and aggregation of poly(3-hexylthiophene). J Mater Chem C 2013;1:5638-46. DOI

99. Kleemann H, Schuenemann C, Zakhidov AA, Riede M, Lüssem B, Leo K. Structural phase transition in pentacene caused by molecular doping and its effect on charge carrier mobility. Org Electron 2012;13:58-65. DOI

100. Scholes DT, Yee PY, Lindemuth JR, et al. The effects of crystallinity on charge transport and the structure of sequentially processed F4TCNQ-doped conjugated polymer films. Adv Funct Mater 2017;27:1702654. DOI

101. Yao H, Fan Z, Cheng H, et al. Recent development of thermoelectric polymers and composites. Macromol Rapid Comm 2018;39:1700727. DOI PubMed

102. Fan Z, Li P, Du D, Ouyang J. Significantly enhanced thermoelectric properties of PEDOT:PSS films through sequential posttreatments with common acids and bases. Adv Energy Mater 2017;7:1602116. DOI

103. Kim JY, Jung JH, Lee DE, Joo J. Enhancement of electrical conductivity of poly(3,4-ethylenedioxythiophene)poly(4styrenesulfonate) by a change of solvents. Synthetic Met 2002;126:311-6. DOI

104. Luo J, Billep D, Waechtler T, et al. Enhancement of the thermoelectric properties of PEDOT:PSS thin films by post-treatment. $J$ Mater Chem A 2013;1:7576-83. DOI

105. Mengistie DA, Chen CH, Boopathi KM, Pranoto FW, Li LJ, Chu CW. Enhanced thermoelectric performance of PEDOT:PSS flexible bulky papers by treatment with secondary dopants. ACS Appl Mater Interfaces 2015;7:94-100. DOI PubMed

106. Fan Z, Du D, Yu Z, Li P, Xia Y, Ouyang J. Significant enhancement in the thermoelectric properties of PEDOT:PSS films through a treatment with organic solutions of inorganic salts. ACS Appl Mater Interfaces 2016;8:23204-11. DOI PubMed

107. Kim N, Kee S, Lee SH, et al. Highly conductive PEDOT:PSS nanofibrils induced by solution-processed crystallization. Adv Mater 2014;26:2268-72. DOI PubMed

108. Xia Y, Sun K, Ouyang J. Solution-processed metallic conducting polymer films as transparent electrode of optoelectronic devices. Adv Mater 2012;24:2436-40. DOI PubMed

109. Rajasekaran P, Muthuraman B. Effect of plasma pre-treatment on the conductivity of polypyrrole-coated cotton fabric. Fibers and Polymers 2019;20:2114-9. DOI

110. Bashir T, Ali M, Cho SW, Persson NK, Skrifvars M. OCVD polymerization of PEDOT: effect of pre-treatment steps on PEDOTcoated conductive fibers and a morphological study of PEDOT distribution on textile yarns. Polym Advan Technol 2013;24:210-9. DOI

111. Liu M, Qin XY. Enhanced thermoelectric performance through energy-filtering effects in nanocomposites dispersed with metallic particles. Appl Phys Lett 2012;101:132103. DOI

112. Ko DK, Kang Y, Murray CB. Enhanced thermopower via carrier energy filtering in solution-processable $\mathrm{Pt}_{-} \mathrm{Sb}_{2} \mathrm{Te}_{3}$ nanocomposites. Nano Lett 2011;11:2841-4. DOI PubMed

113. Coates NE, Yee SK, McCulloch B, et al. Effect of interfacial properties on polymer-nanocrystal thermoelectric transport. Adv Mater 2013;25:1629-33. DOI PubMed

114. Marrocchi A, Lanari D, Facchetti A, Vaccaro L. Poly(3-hexylthiophene): synthetic methodologies and properties in bulk heterojunction solar cells. Energy Environ Sci 2012;5:8457-74. DOI

115. Zhang L, Shi XL, Yang YL, Chen ZG. Flexible thermoelectric materials and devices: from materials to applications. Mater Today 2021;46:62-108. DOI

116. Sun Y, Yang Y, Shi XL, Suo G, Lu S, Chen ZG. Self-standing and high-performance B4C/Sn/acetylene black@reduced graphene oxide films as sodium-ion half/full battery anodes. Appl Mater Today 2021;24:101137. DOI

117. Park J, Lee A, Yim Y, Han E. Electrical and thermal properties of PEDOT:PSS films doped with carbon nanotubes. Synthetic Met 2011;161:523-7. DOI

118. Zelikman E, Narkis M, Siegmann A, Valentini L, Kenny JM. Polyaniline/multiwalled carbon nanotube systems: dispersion of CNT and CNT/PANI interaction. Polymer Engineering \& Science 2008;48:1872-7. DOI

119. Wang J, Cai K, Shen S, Yin J. Preparation and thermoelectric properties of multi-walled carbon nanotubes/polypyrrole composites. Synthetic Met 2014;195:132-6. DOI

120. Nandihalli N, Liu CJ, Mori T. Polymer based thermoelectric nanocomposite materials and devices: fabrication and characteristics. Nano Energy 2020;78:105186. DOI

121. Lee W, Hong CT, Kwon OH, et al. Enhanced thermoelectric performance of bar-coated SWCNT/P3HT thin films. ACS Appl Mater Interfaces 2015;7:6550-6. DOI PubMed

122. Hong CT, Kang YH, Ryu J, Cho SY, Jang KS. Spray-printed CNT/P3HT organic thermoelectric films and power generators. J Mater 
Chem A 2015;3:21428-33. DOI

123. Qu S, Yao Q, Wang L, et al. Highly anisotropic P3HT films with enhanced thermoelectric performance via organic small molecule epitaxy. NPG Asia Mater 2016;8:e292. DOI

124. Hynynen J, Kiefer D, Müller C. Influence of crystallinity on the thermoelectric power factor of P3HT vapour-doped with F4TCNQ. RSC Adv 2018;8:1593-9. DOI

125. Jang E, Poosapati A, Madan D. Enhanced thermoelectric properties of F4TCNQ doped P3HT and its use as a binder for $\mathrm{Sb}_{2} \mathrm{Te}_{3}$ based printed thermoelectric films. ACS Appl Energy Mater 2018;1:1455-62. DOI

126. Untilova V, Biskup T, Biniek L, Vijayakumar V, Brinkmann M. Control of chain alignment and crystallization helps enhance charge conductivities and thermoelectric power factors in sequentially doped P3HT:F4TCNQ films. Macromolecules 2020;53:2441-53. DOI

127. Kang YH, Ko SJ, Lee MH, Lee YK, Kim BJ, Cho SY. Highly efficient and air stable thermoelectric devices of poly(3hexylthiophene) by dual doping of Au metal precursors. Nano Energy 2021;82:105681. DOI

128. Tonga M. A rational ternary design of P3HT/insulating polymers-CNTs/P3HT for the enhanced thermoelectric performances. Compos Interface 2021. DOI

129. Wu L, Li H, Chai H, Xu Q, Chen Y, Chen L. Anion-dependent molecular doping and charge transport in ferric salt-doped P3HT for thermoelectric application. ACS Appl Electron Mater 2021;3:1252-9. DOI

130. Untilova V, Zeng H, Durand P, Herrmann L, Leclerc N, Brinkmann M. Intercalation and ordering of F6TCNNQ and F4TCNQ dopants in regioregular poly(3-hexylthiophene) crystals: impact on anisotropic thermoelectric properties of oriented thin films. Macromolecules 2021;54:6073-84. DOI

131. Xiong J, Jiang F, Shi H, et al. Liquid exfoliated graphene as dopant for improving the thermoelectric power factor of conductive PEDOT:PSS nanofilm with hydrazine treatment. ACS Appl Mater Interfaces 2015;7:14917-25. DOI PubMed

132. Bae EJ, Kang YH, Jang KS, Cho SY. Enhancement of thermoelectric properties of PEDOT:PSS and tellurium-PEDOT:PSS hybrid composites by simple chemical treatment. Sci Rep 2016;6:18805. DOI PubMed PMC

133. Lee HM, Anoop G, Lee HJ, Kim WS, Jo JY. Key parameters for enhancing the thermoelectric power factor of PEDOT:PSS/PANICSA multilayer thin films. RSC Adv 2019;9:11595-601. DOI

134. Jeong MH, Sanger A, Kang SB, Jung YS, Oh IS, et al. Increasing the thermoelectric power factor of solvent-treated PEDOT:PSS thin films on PDMS by stretching. J Mater Chem A 2018;6:15621-9. DOI

135. Kim JY, Lee W, Kang YH, Cho SY, Jang KS. Wet-spinning and post-treatment of CNT/PEDOT:PSS composites for use in organic fiber-based thermoelectric generators. Carbon 2018;133:293-9. DOI

136. Meng Q, Jiang Q, Cai K, Chen L. Preparation and thermoelectric properties of PEDOT:PSS coated Te nanorod/PEDOT:PSS composite films. Org Electron 2019;64:79-85. DOI

137. Kim Y, Lund A, Noh H, et al. Robust PEDOT:PSS wet-spun fibers for thermoelectric textiles. Macromol Mater Eng 2020;305:1900749. DOI

138. Yemata TA, Zheng Y, Kyaw AKK, et al. Modulation of the doping level of PEDOT:PSS film by treatment with hydrazine to improve the Seebeck coefficient. RSC Adv 2020;10:1786-92. DOI

139. El-Shamy AG. Acido-treatment of PEDOT:PSS/Carbon Dots (CDots) nano-composite films for high thermoelectric power factor performance and generator. Mater Chem Phys 2021;257:123762. DOI

140. Lu Y, Li X, Cai K, et al. Enhanced-performance PEDOT:PSS/Cu $/ \mathrm{Cu}_{2} \mathrm{Se}$-based composite films for wearable thermoelectric power generators. ACS Appl Mater Interfaces 2021;13:631-8. DOI PubMed

141. Yang J, Jia Y, Liu Y, et al. PEDOT:PSS/PVA/Te ternary composite fibers toward flexible thermoelectric generator. Compos Commun 2021;27:100855. DOI

142. Deng W, Deng L, Li Z, Zhang Y, Chen G. Synergistically boosting thermoelectric performance of PEDOT:PSS/SWCNT composites via the ion-exchange effect and promoting SWCNT dispersion by the ionic liquid. ACS Appl Mater Interfaces 2021;13:12131-40. DOI PubMed

143. El-Shamy A. The role of nitrogen-carbon dots (NC) nano-particles in enhancing thermoelectric power functions of PEDOT:PSS/Te nano-composite films. Chem Eng J 2021;417:129212. DOI

144. Tu S, Tian T, Lena Oechsle A, et al. Improvement of the thermoelectric properties of PEDOT:PSS films via DMSO addition and DMSO/salt post-treatment resolved from a fundamental view. Chem Eng J 2022;429:132295. DOI

145. Wang L, Yao Q, Bi H, et al. PANI/graphene nanocomposite films with high thermoelectric properties by enhanced molecular ordering. J Mater Chem A 2015;3:7086-92. DOI

146. Wang L, Yao Q, Qu S, Shi W, Chen L. Influence of electronic type of SWNTs on the thermoelectric properties of SWNTs/PANI composite films. Org Electron 2016;39:146-52. DOI

147. Erden F, Li H, Wang X, Wang F, He C. High-performance thermoelectric materials based on ternary $\mathrm{TiO}_{2} / \mathrm{CNT} / \mathrm{PANI}$ composites. Phys Chem Chem Phys 2018;20:9411-8. DOI PubMed

148. Wang Y, Yu C, Liu G, Sheng M, Deng Y. An effective thermal treatment strategy for thermoelectric performance enhancement in PANI/Te nanorod hybrid film. Mater Lett 2018;229:293-6. DOI

149. Shalini V, Navaneethan M, Harish S, et al. Design and fabrication of PANI/GO nanocomposite for enhanced room-temperature thermoelectric application. Appl Surf Sci 2019;493:1350-60. DOI

150. Park D, Kim M, Kim J. High-performance PANI-coated $\mathrm{Ag}_{2} \mathrm{Se}$ nanowire and PVDF thermoelectric composite film for flexible energy harvesting. J Alloys Compd 2021;884:161098. DOI

151. Xu W, Zhao Y, Wang H, et al. Postsynthetic-modified PANI/MOF composites with tunable thermoelectric and photoelectric properties. Chemistry 2021;27:5011-8. DOI PubMed 
152. Sharma S, Singh HH, Kumar S, Khare N. PANI coupled hierarchical Bi2S3 nanoflowers based hybrid nanocomposite for enhanced thermoelectric performance. Nanotechnology 2021;32:335705. DOI PubMed

153. Li H, Liang Y, Liu Y, et al. Engineering doping level for enhanced thermoelectric performance of carbon nanotubes/polyaniline composites. Compos Sci Technol 2021;210:108797. DOI

154. Kim SJ, We JH, Cho BJ. A wearable thermoelectric generator fabricated on a glass fabric. Energy Environ Sci 2014;7:1959-65. DOI

155. We JH, Kim SJ, Cho BJ. Hybrid composite of screen-printed inorganic thermoelectric film and organic conducting polymer for flexible thermoelectric power generator. Energy 2014;73:506-12. DOI

156. Hewitt CA, Montgomery DS, Barbalace RL, Carlson RD, Carroll DL. Improved thermoelectric power output from multilayered polyethylenimine doped carbon nanotube based organic composites. $J$ Appl Phys 2014;115:184502. DOI

157. Dun $\mathrm{C}$, Hewitt $\mathrm{CA}$, Huang $\mathrm{H}$, et al. Flexible $\mathrm{n}$-type thermoelectric films based on $\mathrm{Cu}$-doped $\mathrm{Bi}_{2} \mathrm{Se}_{3}$ nanoplate and Polyvinylidene Fluoride composite with decoupled Seebeck coefficient and electrical conductivity. Nano Energy 2015;18:306-14. DOI

158. Zhu W, Deng Y, Gao M, Wang Y. Hierarchical Bi-Te based flexible thin-film solar thermoelectric generator with light sensing feature. Energ Convers Manage 2015;106:1192-200. DOI

159. Lu Z, Zhang H, Mao C, Li CM. Silk fabric-based wearable thermoelectric generator for energy harvesting from the human body. Appl Energ 2016;164:57-63. DOI

160. Siddique ARM, Rabari R, Mahmud S, Heyst BV. Thermal energy harvesting from the human body using flexible thermoelectric generator (FTEG) fabricated by a dispenser printing technique. Energy 2016;115:1081-91. DOI

161. Jung KK, Jung Y, Choi CJ, Lee JM, Ko JS. Flexible thermoelectric generator with polydimethyl siloxane in thermoelectric material and substrate. Curr Appl Phys 2016;16:1442-8. DOI

162. Oh JY, Lee JH, Han SW, et al. Chemically exfoliated transition metal dichalcogenide nanosheet-based wearable thermoelectric generators. Energy Environ Sci 2016;9:1696-705. DOI

163. Liu H, Wang Y, Mei D, Shi Y, Chen Z. Design of a wearable thermoelectric generator for harvesting human body energy. In: Yang C, Virk G, Yang H. (eds) Wearable sensors and robots. Lecture Notes in Electrical Engineering. Singapore: Springer; 2017. p. 55-66. DOI

164. Wu Q, Hu J. A novel design for a wearable thermoelectric generator based on 3D fabric structure. Smart Mater Struct 2017;26:045037. DOI

165. Shi Y, Wang Y, Mei D, Feng B, Chen Z. Design and fabrication of wearable thermoelectric generator device for heat harvesting. IEEE Robotics and Automation Letters 2018;3:373-8. DOI

166. Francioso L, De Pascali C, Sglavo V, Grazioli A, Masieri M, Siciliano P. Modelling, fabrication and experimental testing of an heat sink free wearable thermoelectric generator. Energ Convers Manage 2017;145:204-13. DOI

167. Wang Y, Shi Y, Mei D, Chen Z. Wearable thermoelectric generator to harvest body heat for powering a miniaturized accelerometer. Appl Energ 2018;215:690-8. DOI

168. Shi Y, Wang Y, Mei D, Chen Z. Wearable thermoelectric generator with copper foam as the heat sink for body heat harvesting. IEEE Access 2018;6:43602-11. DOI

169. Allison LK, Andrew TL. A wearable all-fabric thermoelectric generator. Adv Mater Technol 2019;4:1800615. DOI

170. Choi J, Jung Y, Dun C, et al. High-performance, wearable thermoelectric generator based on a highly aligned carbon nanotube sheet. ACS Appl Energy Mater 2020;3:1199-206. DOI

171. Wen DL, Deng HT, Liu X, Li GK, Zhang XR, Zhang XS. Wearable multi-sensing double-chain thermoelectric generator. Microsyst Nanoeng 2020;6:68. DOI PubMed PMC

172. Yuan J, Zhu R. A fully self-powered wearable monitoring system with systematically optimized flexible thermoelectric generator. Appl Energ 2020;271:115250. DOI

173. Wang Y, Zhu W, Deng Y, Fu B, Zhu P, et al. Self-powered wearable pressure sensing system for continuous healthcare monitoring enabled by flexible thin-film thermoelectric generator. Nano Energy 2020;73:104773. DOI

174. Liu D, Zhao Y, Yan Z, et al. Screen-printed flexible thermoelectric device based on hybrid silver selenide/PVP composite films. Nanomaterials (Basel) 2021;11:20242. DOI PubMed PMC

175. Padmanabhan Ramesh V, Sargolzaeiaval Y, Neumann T, et al. Flexible thermoelectric generator with liquid metal interconnects and low thermal conductivity silicone filler. npj Flexible Electronics 2021;5:5. DOI

176. Müller D, Rambo CR, Recouvreux DOS, Porto LM, Barra GMO. Chemical in situ polymerization of polypyrrole on bacterial cellulose nanofibers. Synthetic Met 2011;161:106-11. DOI

177. TyV, Efimov ON. Polypyrrole: a conducting polymer; its synthesis, properties and applications. Russian Chemical Reviews 1997;66:443-57. DOI

178. Cooper W. Notes: synthesis 2-trifluoroacetylpyrole. J Org Chem 1958;23:1382. DOI

179. Rapi S, Bocchi V, Gardini GP. Conducting polypyrrole by chemical synthesis in water. Synthetic Met 1988;24:217-21. DOI

180. Sabouraud G, Sadki S, Brodie N. The mechanisms of pyrrole electropolymerization. Chem Soc Rev 2000;29:283-93. DOI PubMed

181. Paul S, Karambelkar VV, Ekhe J. Experimental design of high yield polypyrrole by Taguchi method. Int J Eng Res Appl 2013;3:8995. DOI

182. Liang L, Chen G, Guo CY. Polypyrrole nanostructures and their thermoelectric performance. Mater Chem Front 2017;1:380-6. DOI

183. Du Y, Niu H, Li J, et al. Morphologies Tuning of polypyrrole and thermoelectric properties of polypyrrole nanowire/graphene composites. Polymers (Basel) 2018;10:1143. DOI PubMed PMC

184. Wu F, Xie A, Sun M, Wang Y, Wang M. Reduced graphene oxide (RGO) modified spongelike polypyrrole (PPy) aerogel for excellent electromagnetic absorption. J Mater Chem A 2015;3:14358-69. DOI 
185. Chatterjee M, Mitra M, Banerjee D. Thermoelectric performance of polypyrrole and single walled carbon nanotube composite. Mater Today P 2018;5:9743-8. DOI

186. Bharti M, Singh A, Samanta S, et al. Flexo-green polypyrrole - silver nanocomposite films for thermoelectric power generation. Energ Convers Manage 2017;144:143-52. DOI

187. Bharti M, Jha P, Singh A, et al. Scalable free-standing polypyrrole films for wrist-band type flexible thermoelectric power generator. Energy 2019;176:853-60. DOI

188. Heeger AJ. Nobel lecture: semiconducting and metallic polymers: the fourth generation of polymeric materials. Rev Mod Phys 2001;73:681-700. DOI

189. Chiang JC, MacDiarmid AG. 'Polyaniline': protonic acid doping of the emeraldine form to the metallic regime. Synthetic Met 1986;13:193-205. DOI

190. Wu R, Yuan H, Liu C, Lan JL, Yang X, Lin YH. Flexible PANI/SWCNT thermoelectric films with ultrahigh electrical conductivity. RSC Adv 2018;8:26011-9. DOI

191. Chatterjee MJ, Banerjee D, Chatterjee K. Composite of single walled carbon nanotube and sulfosalicylic acid doped polyaniline: a thermoelectric material. Mater Res Express 2016;3:085009. DOI

192. Hsieh YY, Zhang Y, Zhang L, et al. High thermoelectric power-factor composites based on flexible three-dimensional graphene and polyaniline. Nanoscale 2019;11:6552-60. DOI PubMed

193. Jonas F, Heywang G, Schmidtberg W, Heinze J, Dietrich M. Polythiophenes, process for their preparation and their use. Available from: https://patents.google.com/patent/US4987042A/en. [Last accessed on 28 Sep 2021].

194. Groenendaal L, Zotti G, Aubert PH, Waybright SM, Reynolds JR. Electrochemistry of poly(3,4-alkylenedioxythiophene) derivatives. Adv Mater 2003;15:11. DOI

195. Heywang G, Jonas F. Poly(alkylenedioxythiophene)s-new, very stable conducting polymers. Adv Mater 1992;4:116-8. DOI

196. Sun K, Zhang S, Li P, et al. Review on application of PEDOTs and PEDOT:PSS in energy conversion and storage devices. $J$ Mater Sci Mater El 2015;26:4438-62. DOI

197. Jia Y, Shen L, Liu J, et al. An efficient PEDOT-coated textile for wearable thermoelectric generators and strain sensors. $J$ Mater Chem C 2019;7:3496-502. DOI

198. Ni D, Song H, Chen Y, Cai K. Free-standing highly conducting PEDOT films for flexible thermoelectric generator. Energy (Oxford) 2019;170:53-61. DOI

199. Khoso NA, Ahmed A, Deb H, et al. Controlled template-free in-situ polymerization of PEDOT for enhanced thermoelectric performance on textile substrate. Org Electron 2019;75:105368. DOI

200. Kim B, Cho C, Han M, Attias AJ, Kim E. Giant photo-magneto-thermoelectric effect of end-on oriented PEDOT grown from selfassembled 3D tectons. Adv Funct Mater 2021. DOI

201. Geoghegan M, Hadziioannou G. Polymer electronics. Oxford: Oxford University Press; 2013.

202. Yoo D, Kim J, Kim JH. Direct synthesis of highly conductive poly(3,4-ethylenedioxythiophene):poly(4-styrenesulfonate) (PEDOT:PSS)/graphene composites and their applications in energy harvesting systems. Nano Res 2014;7:717-30. DOI

203. Xu S, Hong M, Shi XL, et al. High-performance PEDOT:PSS flexible thermoelectric materials and their devices by triple posttreatments. Chem Mater 2019;31:5238-44. DOI

204. Wang Y, Hong M, Liu WD, et al. $\mathrm{Bi}_{0.5} \mathrm{Sb}_{1.5} \mathrm{Te}_{3} /$ PEDOT:PSS-based flexible thermoelectric film and device. Chem Eng $J$ 2020;397:125360. DOI

205. Wen N, Fan Z, Yang S, et al. Highly conductive, ultra-flexible and continuously processable PEDOT:PSS fibers with high thermoelectric properties for wearable energy harvesting. Nano Energy 2020;78:105361. DOI

206. Kim CS, Lee GS, Choi H, et al. Structural design of a flexible thermoelectric power generator for wearable applications. Applied Energy 2018;214:131-8. DOI

207. Lan X, Wang T, Liu C, et al. A high performance all-organic thermoelectric fiber generator towards promising wearable electron. Compos Sci Technol 2019;182:107767. DOI

208. Mccullough RD. The chemistry of conducting polythiophenes. Adv Mater 1998;10:93-116. DOI

209. Quagliotto P, Fin A. Advances in synthetic methods for the preparation of poly(3- hexylthiophene) (P3HT). LOC 2018;15:991-1006. DOI

210. Lim E, Peterson KA, Su GM, Chabinyc ML. Thermoelectric properties of poly(3-hexylthiophene) (P3HT) doped with 2,3,5,6tetrafluoro-7,7,8,8-tetracyanoquinodimethane (F4TCNQ) by vapor-phase infiltration. Chem Mater 2018;30:998-1010. DOI

211. Qu S, Wang M, Chen Y, Yao Q, Chen L. Enhanced thermoelectric performance of CNT/P3HT composites with low CNT content. RSC Adv 2018;8:33855-63. DOI

212. Zhou H, Zhang Z, Sun C, Deng H, Fu Q. Biomimetic approach to facilitate the high filler content in free-standing and flexible thermoelectric polymer composite films based on PVDF and $\mathrm{Ag}_{2}$ Se nanowires. ACS Appl Mater Interfaces 2020;12:51506-16. DOI PubMed

213. Kumar A, Kumar R, Satapathy DK. $\mathrm{Bi}_{2} \mathrm{Se}_{3}-\mathrm{PVDF}$ composite: a flexible thermoelectric system. Physica B: Condensed Matter 2020;593:412275. DOI

214. Suemori K, Uemura S. High thermoelectric performance of post mechanical treated carbon nanotube films with polystyrene binder. Appl Phys Lett 2020;116:081902. DOI

215. Suemori K, Hoshino S, Kamata T. Flexible and lightweight thermoelectric generators composed of carbon nanotube-polystyrene composites printed on film substrate. Appl Phys Lett 2013;103:153902. DOI

216. Wan K, Taroni PJ, Liu Z, et al. Flexible and stretchable self-powered multi-sensors based on the N-type thermoelectric response of 
polyurethane $/ \mathrm{Na}_{\mathrm{x}}(\mathrm{Ni}-\mathrm{ett})_{\mathrm{n}}$ composites. Adv Electron Mater 2019;5:1900582. DOI

217. Liu L, Sun Y, Li W, et al. Flexible unipolar thermoelectric devices based on patterned poly[ $\mathrm{K}_{\mathrm{x}}($ Ni-ethylenetetrathiolate $\left.)\right]$ thin films. Mater Chem Front 2017;1:2111-6. DOI

218. Wang L, Zhang Z, Liu Y, et al. Exceptional thermoelectric properties of flexible organic-inorganic hybrids with monodispersed and periodic nanophase. Nat Commun 2018;9:3817. DOI PubMed PMC

219. Na Z, Wang X, Liu X, Li W, Sun X. O/N/S trifunctional doping on graphite felts: A novel strategy toward performance boosting of cerium-based redox flow batteries. Carbon Energy 2021. DOI

220. Luo D, Wang R, Yu W, Zhou W. A novel optimization method for thermoelectric module used in waste heat recovery. Energy Convers Manag 2020;209:112645. DOI

221. Zhou N, Hu Z, Nasser R, Song J. Thermoelectric properties of PbSe nanocomposites from solution-processed building blocks. ACS Appl Energy Mater 2021;4:2014-9. DOI

222. Finn PA, Asker C, Wan K, Bilotti E, Fenwick O, Nielsen CB. Thermoelectric materials: current status and future challenges. Front Electron Mater 2021;1:677845. DOI

223. Jin W, Liu L, Yang T, et al. Exploring Peltier effect in organic thermoelectric films. Nat Commun 2018;9:3586. DOI PubMed PMC

224. Wang S, Sun H, Ail U, et al. Thermoelectric properties of solution-processed n-doped ladder-type conducting polymers. Adv Mater 2016;28:10764-71. DOI PubMed

225. Lu Y, Yu ZD, Zhang RZ, et al. Rigid coplanar polymers for stable n-type polymer thermoelectrics. Angew Chem Int Ed Engl 2019;58:11390-4. DOI PubMed

226. Naab BD, Gu X, Kurosawa T, To JWF, Salleo A, Bao Z. Role of polymer structure on the conductivity of n-doped polymers. Adv Electron Mater 2016;2:1600004. DOI

227. Schlitz RA, Brunetti FG, Glaudell AM, et al. Solubility-limited extrinsic n-type doping of a high electron mobility polymer for thermoelectric applications. Adv Mater 2014;26:2825-30. DOI PubMed

228. Zhao X, Madan D, Cheng Y, et al. High conductivity and electron-transfer validation in an n-type fluoride-anion-doped polymer for thermoelectrics in air. Adv Mater 2017;29:1606928. DOI PubMed

229. Chen G, Xu W, Zhu D. Recent advances in organic polymer thermoelectric composites. J Mater Chem C 2017;5:4350-60. DOI

230. Peng S, Wang D, Lu J, et al. A review on organic polymer-based thermoelectric materials. J Polym Environ 2017;25:1208-18. DOI

231. Li B, Li X, Yang F, et al. Enhanced thermoelectric performance of a donor-acceptor-based two-dimensional conjugated polymer with high crystallinity. ACS Appl Energy Mater 2021;4:4662-71. DOI

232. Xie DX, Liu TC, Xiao J, Fang JK, Pan CJ, Shao G. Effect of side chain substituent volume on thermoelectric properties of IDT-based conjugated polymers. Molecules 2021;26:963. DOI PubMed PMC

233. Qu D, Li X, Wang H, Chen G. Assembly strategy and performance evaluation of flexible thermoelectric devices. Adv Sci (Weinh) 2019;6:1900584. DOI PubMed PMC

234. Qu D, Huang X, Li X, Wang H, Chen G. Annular flexible thermoelectric devices with integrated-module architecture. npj Flex Electron 2020;4:1. DOI

235. Nguyen Huu T, Nguyen Van T, Takahito O. Flexible thermoelectric power generator with Y-type structure using electrochemical deposition process. Applied Energy 2018;210:467-76. DOI

236. Trung NH, Van Toan N, Ono T. Fabrication of $\pi$-type flexible thermoelectric generators using an electrochemical deposition method for thermal energy harvesting applications at room temperature. J Micromech Microeng 2017;27:125006. DOI

237. Amagai Y, Shimazaki T, Okawa K, Fujiki H, Kawae T, Kaneko N. Precise measurement of absolute Seebeck coefficient from Thomson effect using ac-dc technique. AIP Advances 2019;9:065312. DOI

238. Pope A, Zawilski B, Tritt T. Description of removable sample mount apparatus for rapid thermal conductivity measurements. Cryogenics 2001;41:725-31. DOI

239. Vandersande JW, Pohl RO. Simple apparatus for the measurement of thermal diffusivity between $80-500 \mathrm{~K}$ using the modified Ångström method. Rev Sci Instrum 1980;51:1694-9. DOI

240. Wei G, Liu Y, Zhang X, Yu F, Du X. Thermal conductivities study on silica aerogel and its composite insulation materials. Int $J$ Heat Mass Tran 2011;54:2355-66. DOI

241. Stabler FR. Commercialization of thermoelectric technology. MRS Online Proceedings Library 2005;886:104. DOI

242. Tkachov R, Stepien L, Grafe R, et al. Polyethenetetrathiolate or polytetrathiooxalate? Improved synthesis, a comparative analysis of a prominent thermoelectric polymer and implications to the charge transport mechanism. Polym Chem 2018;9:4543. DOI

243. Hou W, Nie X, Zhao W, et al. Fabrication and excellent performances of $\mathrm{Bi}_{0.5} \mathrm{Sb}_{1.5} \mathrm{Te}_{3}$ /epoxy flexible thermoelectric cooling devices. Nano Energy 2018;50:766. DOI 